Article

\title{
A Tool for the Evaluation of Energy-Environmental Retrofit Interventions on Opaque Walls Using ETICS
}

\author{
Pierfrancesco Fiore *(D), Giuseppe Donnarumma *(D) and Carmelo Falce \\ Department of Civil Engineering, University of Salerno, 84084 Fisciano (SA), Italy; cfalce@unisa.it \\ * Correspondence: pfiore@unisa.it (P.F.); gidonnarumma@unisa.it (G.D.); Tel.: +39-089-96-4127 (P.F.)
}

\begin{abstract}
Buildings in Europe are the largest consumers of energy, since they are responsible for $40 \%$ of energy consumption and $36 \%$ of pollutant gas emissions. The energy efficiency, the consequential economic savings and the reduction of environmental impacts must necessarily consider the design of improvements that affect the opaque vertical envelope of a building. The vertical envelope generally constitutes the largest dispersing surface. In this paper, a comparative evaluation of different ETICS (External Thermal Insulation Composite System) solutions through the application of a multicriteria decision support method is proposed. The criteria at the basis of the procedure relate to the energy, environmental, indoor comfort, and economic aspects. Through the application to the case study, consisting of two types of vertical walls with reference to three different climate zones, the ETICS alternative that achieves the best compromise between the various evaluation criteria is highlighted and the solidity of the method itself is tested. The potential of the methodology in the analysis of the alternatives in adherence to individual subcriteria and the possibility of implementation with additional indicators as the needs change are also highlighted. The social impact is undoubtedly one of the expected effects of the application of the method, since a better performance of the building envelope leads to an increase in comfort and liveability of indoor spaces. Moreover, all studies aimed at increasing the performance of the building or parts of it, consequently, lead to greater accessibility by the most vulnerable members of society, in line with the principles of sustainability and inclusiveness of the United Nations 2030 Agenda.
\end{abstract} Falce, C. A Tool for the Evaluation of Energy-Environmental Retrofit Interventions on Opaque Walls Using ETICS. Sustainability 2021, 13, 4063. https://doi.org/10.3390/su13074063

Academic Editor: Giuseppe Margani

Received: 28 January 2021

Accepted: 2 April 2021

Published: 6 April 2021

Publisher's Note: MDPI stays neutral with regard to jurisdictional claims in published maps and institutional affiliations.

Copyright: (c) 2021 by the authors. Licensee MDPI, Basel, Switzerland. This article is an open access article distributed under the terms and conditions of the Creative Commons Attribution (CC BY) license (https:// creativecommons.org/licenses/by/ $4.0 /)$.

Keywords: ETICS; thermal insulation; comfort indoor; opaque walls; energy-environmental retrofit; multicriteria analysis

\section{Introduction}

Approximately $50 \%$ of the capital invested in the developed world is consumed by the construction industry, and $70 \%$ of that amount is used in existing constructions. Scientific research [1,2] claims that the construction sector uses $50 \%$ of the raw materials processed across the planet and is responsible for the production of 30\% of greenhouse gas emissions.

Therefore, intervening in the construction landscape, with particular emphasis on the existing building stock, represents a correct strategy for the reduction of significantly impacting anthropogenic activities. This direction has been taken by the United Nations (UN) since 2015 when the member countries signed the 2030 Agenda for Sustainable Development [3] that includes 17 'Sustainable Development Goals and targets' (SDGs), including ensuring access to affordable, reliable, sustainable, and modern energy for all (Goal 7); making cities and human settlements inclusive, safe, resilient, and sustainable (Goal 11); acting urgently to combat climate change and its impacts (Goal 13).

In the European context, buildings are the largest consumer of energy, being responsible for $40 \%$ of energy consumption and $36 \%$ of pollutant gas emissions [4]. Furthermore, the construction sector is responsible for the production of $36.4 \%$ of the total amount of waste in the EU 28 [5].

Considering a potential energy saving of $6 \%$ of the EU's total energy consumption [6], the European Commission has for some years now launched strategies to improve the 
existing building stock through the renovation of public and private buildings as part of the European Green Deal [7] in order to pursue significant energy savings in the building sector through a range of actions [8-12]. In Italy, the data are in line with the European ones, considering that almost $40 \%$ of final energy consumption (and more than $36 \%$ of greenhouse gas emissions) comes from buildings. In fact, $75 \%$ of buildings do not meet high energy efficiency standards [13].

The publication of the Piano Nazionale Integrato per l'Energia e il Clima (PNIEC) [14], implementing Regulation (EU) 2018/1999 [15], dates to 21 January 2020 and is intended to represent a radical shift in energy and environmental policy towards the 2030 targets. In the construction sector, the aim is to promote energy efficiency across the board, inevitably also affecting the opaque components of the building envelope. The Italian Government has used the mechanism of tax deductions [16] in order to encourage interventions concerning the requalification of the existing heritage with particular attention to the building envelope. The importance of this building component has been further emphasised by the government's incentive programme for improving the efficiency of opaque walls that disperse outwards, which is subsidised through various deduction rates [17-19]. Law Decree no. 34 of 19 May 2020 (known as the 'Decreto Rilancio') [20] provided for a new concession of considerable financial convenience (known as the 'Superbonus $110 \%$ ') for specific interventions in the field of energy efficiency, antiseismic interventions, installation of photovoltaic systems or infrastructures for recharging electric vehicles in buildings. As far as energy efficiency is concerned, the regulation has included the thermal insulation of opaque envelope closures among the 'driving' measures, i.e., those necessary for the benefit.

Statistics from ENEA, the National Agency for new technologies, energy and sustainable economic development, allow to state that in 2019, at a national level, interventions aimed at upgrading the building envelope represented the actions that made it possible to achieve more than a third of the total energy savings in the building sector [21]. These results were also achieved through the specialisation of the regulatory framework. At a national level, the main legislative reference for the correct design and verification of the characteristics of opaque building envelopes is currently represented by the Ministerial Decree 26 June 2015 [22] which specifically regulates their energy performance on the basis of various parameters of interest. This legislation results from the transposition of Directive 2010/31/EU [7] on the energy performance of buildings which, in conjunction with Directive 2012/27/EU [8] on energy efficiency, was amended by Directive 2018/844/EU [9]. This latter reference takes into account the role played by building insulation systems, encouraging the improvement of their performance and recognising their fundamental value in the pursuit of energy saving objectives.

Energy efficiency and consequent economic savings cannot be achieved without planning improvements to the dispersion surfaces. Facades are generally the largest component of the building [23] and have a strong impact on the final energy consumption for heating, cooling and lighting [24], as they form the separation membrane between inside and outside. The building envelope is mainly responsible for the heat flow through it and has a significant impact on the thermal comfort of the air-conditioned space and the possible demand for additional energy [25]. It is clear that the estimation of thermal gains or losses arising from the building's 'skin' is a fundamental support phase in the decision-making process underlying design or rehabilitation operations [26].

At the present time, numerous studies have specialised in the thermal characterisation of building envelopes, investigating the issues of thermal insulation, the choice of suitable materials, and inertial characteristics in relation to the specifics of the context, in order to further guarantee the thermal comfort and quality of life of the occupants [27-32]. The method proposed in this paper undoubtedly has a social impact, because studies aimed at optimising the performance of buildings or parts of buildings lead to greater accessibility, even for the most vulnerable, to the comfort of buildings, to energy performance and, more generally, to the liveability of indoor spaces. These statements are, moreover, confirmed in 
the principles of sustainability and inclusiveness of the United Nations 2030 Agenda, when it specifies in objective 11 (Make cities and human settlements inclusive, safe, resilient and sustainable) at point 11.c that it is necessary to "Support less developed countries, including with technical and financial assistance, in constructing sustainable and resilient buildings using local materials". It sometimes happens that in socially degraded or poverty-stricken areas, both in cities and in the suburbs, buildings are not constructed (or existing ones are not upgraded) in a sustainable way, with a consequent reduction in comfort, as already mentioned, but also with an uncontrolled production of $\mathrm{CO}_{2}$ that could instead be reduced thanks to what is proposed.

One of the most widely used techniques since the 1990s [33] has been external insulation, ETICS (External Thermal Insulation Composite System): the insulation is applied to the external side of the facade and is covered by a thin finishing layer or coating.

Lujan et al. [34] point out that one of the most effective strategies for the thermal insulation of facades to date is provided by ETICS and in particular they conclude that this system reduces energy losses by $57 \%$ and energy gains by $39 \%$ compared to a cavity wall insulation made of brick. However, despite the improvement of the thermal characteristics of the envelope, such systems can be affected by problems of surface condensation, especially resulting from meteorological phenomena [35]. The research carried out by Sierra-Pérez et al. [36] highlights the environmental implications of using different facade insulation systems, in relation to the materials used and the context. This study aims to compare different systems for improving the efficiency of the opaque building envelope (ETICS, ITICS, ventilated facade) as well as assess the environmental sustainability parameters related to the construction, installation and transport of the new insulation components. This study shows that the most effective systems are ventilated facades coupled with opaque envelope insulation systems, while the least impactful system is ETICS. Similarly, the authors, Donnarumma and Fiore [37], proposed a multicriteria methodology to select the optimal alternative between different energy retrofit techniques, considering both ETICS solutions and ventilated wall systems, overcladding and total facade replacement. Through the application of the model, calibrated according to three different points of view-public administration, private investors and professional technicians - and implemented in three criteria and nine subcriteria, it emerged that the optimal alternative is ETICS with wood fibre.

The study by Bragança et al. [38] reports a comparison between ETICS applied to a traditional cavity brick wall. The analysis specialises in a multicriteria evaluation of the performance and sustainability characteristics related to two insulating materials such as XPS and agglomerated cork. The results indicate that ETICS is the best solution, regardless of the type of insulation material used. In addition, the authors point out that the use of materials derived from renewable sources, despite requiring a higher initial investment than more impactful materials, results in a lower environmental impact that repays the purchase cost.

An important contribution to the assessment of the state of degradation of ETICS and the consequent planning of maintenance operations is provided by the work carried out by Marques et al. [39]. The research consists of applying the Factor Method to predict the service life of various exterior insulation systems by simulating four climatic contexts and evaluating the statistical indicators. Using iterative simulations, the authors estimated an average service life of 21 years for ETICS. The study by Mandilaras et al. [40] focuses on the evaluation of the thermal behaviour of ETICS, proposing a comparison between traditional EPS systems and innovative VIP (Vacuum Insulation Panel) systems. The stratigraphy using VIPs guarantees a higher thermal resistance than the analogous wall insulated with EPS. However, given the much higher cost of VIPs, this contribution makes it clear that the design of insulation systems must be based on a holistic approach to the subject: thermal considerations must be accompanied by economic evaluations in order to fully assess the suitability of the systems under analysis. 
According to the review of the scientific and regulatory literature, it is intended to define a decision-making tool that will help identify the insulation material that best meets the principles of environmental, social and economic sustainability. The choice will be made through the use of the AHP (Analytic Hierarchy Process) method, belonging to the family of multicriteria decision-making methods. The use of multicriteria methods is required to simultaneously consider the different aspects of the concept of sustainability adopting several criteria and subcriteria that will enable to fully analyse the characteristics of the insulating materials that will be compared.

\section{Methodology}

The protocol adopted is structured according to the logic of multicriteria analysis methods [41,42] (MCDA, Multi Criteria Decision Analysis) which allow to support choices in problems influenced by different decision variables and different alternative solutions.

Specifically, the methodology includes the following steps:

1. definition of the purpose (goal) of the comparison;

2. identification of alternatives $\mathrm{Ai}$;

3. selection of the criteria $\mathrm{Cj}$ and any subcriteria for evaluation;

4. attribution of the weights relative to the criteria and subcriteria;

5. construction of the Matrix of Alternatives;

6. normalisation of the matrix values;

7. computation of total scores and ranking of alternatives.

The objective of the analysis-point 1 -is to compare, in terms of energy-environmental and economic sustainability, different ETICS alternatives for the thermal insulation of existing opaque vertical walls.

The comparison of alternatives being analysed was performed through the use of the hierarchical analysis process, AHP. This is a deterministic, single-decision maker method. The force point of the AHP method is represented from the possibility to decompose the main problem in various subproblems of analogous importance. Instead, the steps that require special consideration are the procedures of criteria weighing and normalisation of the values representing the components of the matrix of alternatives. The definition of criteria and subcriteria and their subsequent weighing will be adequately detailed in Section 2.1. Similarly, the normalisation process deserves adequate attention: Section 2.2 will discuss the methods used to normalise the matrix of alternatives. The sequential steps of the method employed are summarised in Figure 1.

It is important to emphasise that AHP provides a solution that is a function of certain parameters, which can be identified in the criteria at the basis of the decision-making process. Therefore, the criteria and their associated indicators must be determined according to the objective to be achieved. Consequently, the evaluation of alternatives can be conducted on the basis of clear, evident and objectively acceptable criteria.

The relative weights are assigned through the construction of the matrices of the pair comparisons, where all the elements (criteria and subcriteria) belonging to the same hierarchical level are compared in pairs in relation to the super ordinate element. The result of the single comparison is an $a_{i j}$ dominance coefficient, which expresses a measure of the relative importance of element $i$ with respect to element $j$. To determine the values of the $a_{i j}$ coefficients, a nine-value "Saaty fundamental scale" [43] or other scales can be used. The Saaty scale correlates the first nine integers with as many judgments as capable of expressing the possible results of the comparison. 


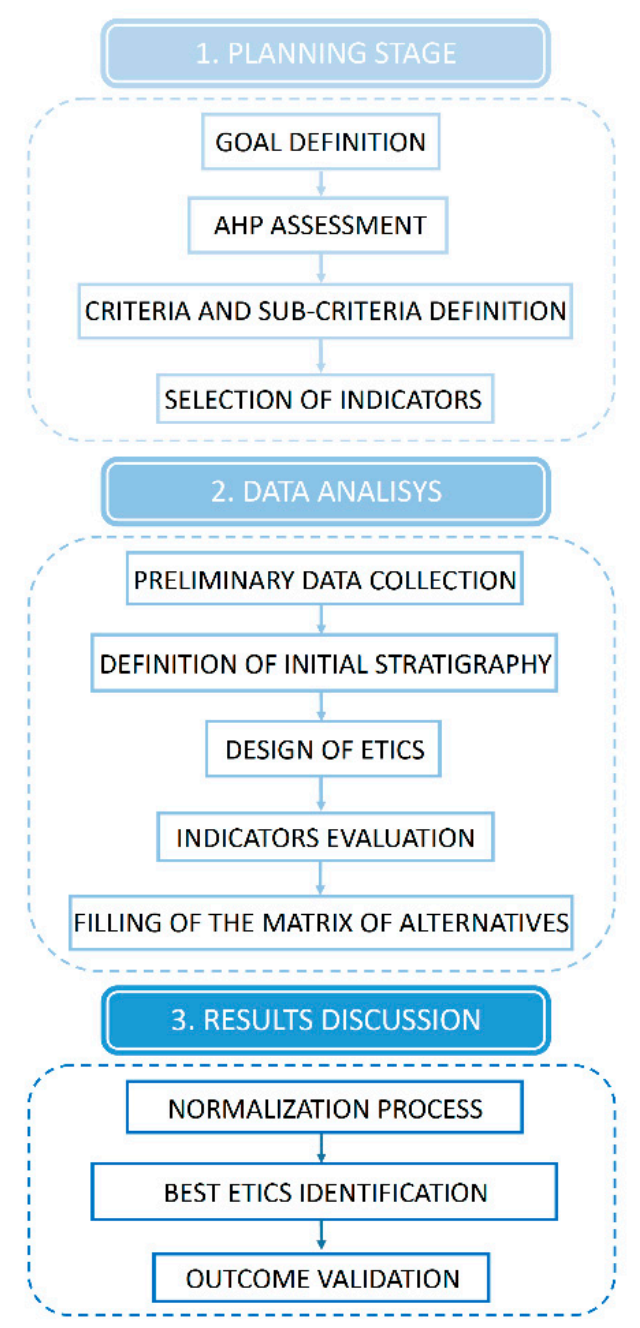

Figure 1. The method's flow chart.

Considering a number $\mathrm{n}$ of elements, the generic matrix of pair comparisons $W$ is a square matrix $(n \times n)$ that is reciprocal and positive. If the matrix $W$ is consistent (i.e., satisfies the properties of reciprocity and transitivity), whose known elements $a_{i j}$ are equal to the ratio between the weights $w_{i} / w_{j}$, the following vector equation applies:

$$
W w=\lambda_{\max } w
$$

where $\lambda_{\max }$ is the maximum eigenvalue, the only non-zero eigenvalue, equal to the order $\mathrm{n}$ of the matrix, while $w$ is the associated eigenvector to which corresponds the vector of the weights, i.e., of the searched variables. In general, the values $a_{i j}$ derive from qualitative judgements that present inconsistencies and therefore from Equation (1), an approximate estimate of the weights can be obtained. The consistency of the values assigned by experts to $w_{i} / w_{j}$ ratios depends on the deviation between $\lambda_{\max }$ and $n$, which tends towards zero when the judgement is consistent. In particular, the consistency index $\mathrm{CI}$ is given by the following:

$$
C I=\frac{\lambda_{\max }-n}{n-1}
$$

where, as the inconsistency increases, the value of $C I$ increases. The $C I$ index should be compared with the Random Consistency Index (RCI), whose value depends on the number $\mathrm{n}$ of variables according to Table 1 . 
Table 1. Random Consistency Index (RCI) values.

\begin{tabular}{cccccccccc}
\hline $\boldsymbol{n}$ & $\mathbf{1}$ & $\mathbf{2}$ & $\mathbf{3}$ & $\mathbf{4}$ & $\mathbf{5}$ & $\mathbf{6}$ & $\mathbf{7}$ & $\mathbf{8}$ & $\mathbf{9}$ \\
\hline $\boldsymbol{R} \boldsymbol{C I}$ & 0 & 0 & 0.58 & 0.90 & 1.12 & 1.24 & 1.32 & 1.41 & 1.45 \\
\hline
\end{tabular}

The consistency ratio, CR (Consistency Ratio) can finally be obtained from the following equation:

$$
C R=\frac{C I}{R C I}
$$

The resulting vector of weights $\mathrm{w}$ can be accepted if:

- $\quad C R<5 \%$ for $n=3$;

- $\quad C R<8 \%$ for $n=4$;

- $\quad C R<10 \%$ for $n>4$.

The next step involves the assembly of the Matrix of Decisions D, of order $n \times m$ (with $n$ number of alternative solutions and $m$ number of judgement criteria) whose elements, under the logic of AHP, are obtained by means of comparison matrices in pairs of alternatives $A_{i}(i=1,2, \ldots, n)$ with respect to each criterion $C_{j}(j=1,2, \ldots, m)$.

The last step involves calculating the total weights of the alternatives through the principle of hierarchical composition, i.e., the local weights of each element are multiplied by those of the corresponding upper elements and finally the products thus obtained are added together [44].

The intervention alternatives, based on what is illustrated in Section 2, are defined in Section 4 in relation to the wall stratigraphies selected for the application of the decision tool.

\subsection{Evaluation Criteria, Subcriteria and Indicators}

Based on the objectives of the analysis, the following evaluation criteria were defined: $C_{1}$ 'Energy performance', $C_{2}$ 'Environmental sustainability', $C_{3}$ 'Indoor comfort', $C_{4}$ 'Economic sustainability'. These criteria were selected with reference to the threefold dimension of the concept of sustainability: environmental (criteria $C_{1}$ and $C_{2}$ ), social (criterion $C_{3}$ ) and economic (criterion $C_{4}$ ). The choice of criteria and their subcriteria was made according to a review of the relevant scientific literature $[36,40]$. From the studies considered, a series of useful indicators were identified to adequately define the environmental, social and cultural spheres connected with the concept of sustainability. The purely technical criteria were taken directly from the sector's regulations. On the other hand, the criteria related to the estimation of economic sustainability were specifically structured to take proper account of the specifics of the case. In order to fully understand the assumptions underlying the proposed decision-making tool, the characterisation of the individual criteria and related subcriteria is set out below, with a subsequent description of the indicators associated with them.

Criterion $C_{1}$ was divided into two subcriteria: $C_{1.1}$ related to heat transfer in steady state and $C_{1.2}$ related to heat transfer in dynamic regime.

The hypothesis of stationary regime (heat flow and constant temperatures in time) is a convenient abstraction that, especially in winter, is motivated by a limited excursion of the external temperature compared to the inside/outside temperature difference.

Under these conditions, the stationary thermal transmittance $U$ is defined as the heat flow through a building element with a surface area of $1 \mathrm{~m}^{2}$ at a temperature difference of $1 \mathrm{~K}$ between inside and outside. Specifically, the stationary transmittance of a facade system, which can be schematised as a set of $\mathrm{n}$ flat, homogeneous and contiguous layers, is given by the following equation:

$$
U=\frac{1}{\frac{1}{h_{i}}+\frac{1}{h_{e}}+\sum_{i=1}^{n} \frac{s_{i}}{\lambda_{i}}}
$$

where $h_{i}$ and $h_{e}$ are the heat transfer coefficients for convection and radiation on the internal side and on the external side, $s_{i}$ is the thickness of the $i$-th layer expressed in $\mathrm{m}$, 
$\lambda_{i}$ is the thermal conductivity of the material of the $i$-th layer expressed in $\mathrm{W} /(\mathrm{mK})$. The unit of $\mathrm{U}$ is therefore $\mathrm{W} /\left(\mathrm{m}^{2} \mathrm{~K}\right)$. If the material of a layer of the envelope system is not homogeneous, an equivalent conductivity value, $\lambda_{\text {eq }}$, can be estimated. More generally, the normative reference for the calculation of the transmittance of opaque structures is UNI EN ISO 6946 [45]. The national territory is divided into six climate zones for each of which the current national standard sets maximum transmittance limits [21].

As already mentioned, the stationary transmittance is not sufficient by itself to adequately describe the energy behaviour of the building envelope, especially regarding the performance quality in the summer season. In this period, in fact, with the same stationary transmittance, the inertial characteristics of the walls take on particular importance, that is the capacity to reduce (damping) and delay (phase shifting) the effect of external dynamic stresses on the thermal load of the internal environment. A particularly useful parameter to describe these inertial effects is the periodic thermal transmittance $Y_{I E}$, defined and determined according to UNI EN ISO 13786:2008 [46] and subsequent updates. The periodic thermal transmittance can be expressed according to the following relationship:

$$
Y_{I E}=f \cdot U
$$

where $f$ is a decrement or attenuation factor related to the ratio of dynamic to stationary heat flux.

The environmental sustainability of the envelope system is assessed both with reference to the recent national legislation on 'Criteri Ambientali Minimi' (CAM), Decree 11 October 2017 [47], and to the reference practice UNI/PdR 13:2019 [48] and the current scientific research guidelines in the sector.

The three subcriteria of environmental sustainability considered are $C_{2.1}$ 'Recycled/ Recovered Materials', $C_{2.2}$ 'Embodied Carbon' and $C_{2.3}$ 'Disassemblable Materials'.

The performance indicator related to criterion $C_{2.1}$ is the percentage by weight of recycled and/or recovered materials used in the intervention in addition to the legal threshold percentage. The percentage of recycled material can be derived from one of the following options:

- a Type III environmental declaration in accordance with EN 15804 [49] and ISO 14025 [50];

- a product certification granted by a conformity assessment body attesting the recycled content;

- a Type II environmental self-declaration in accordance with ISO 14021 [51], verified by a conformity assessment board.

Indicator $C_{2.2}$, Embodied Carbon (EC), is the total emissions of equivalent $\mathrm{CO}_{2} \mathrm{em}$ bedded in materials during their life cycle, from cradle to grave. Generally, only the life cycle phases from cradle to gate, i.e., the phases from raw material supply to the end of the production process, are taken into account. An important and consistent international database for building materials is the ICE database, Inventory of Carbon and Energy, developed by Dr. Craig Jones at the University of Bath [52].

For a given facade system, the indicator can therefore be assessed as follows:

$$
E C_{\text {tot }}=\sum_{i=1}^{n} E C_{i} \cdot P_{i}
$$

where $E C_{i}$ is the Embodied Carbon per unit weight $(\mathrm{kg} \mathrm{CO} 2 \mathrm{eq} / \mathrm{kg})$ for the $i$-th material, $P_{i}$ is the weight in $\mathrm{kg}$ of the $i$-th material constituting the facade.

The performance indicator related to criterion $C_{2.3}$ is the percentage by weight of materials compared to those used in the intervention. It is necessary to verify if the design solutions adopted are able to facilitate the disassembly operations of the constituent elements and allow for their possible reuse and/or recycling. Dry construction systems generally guarantee excellent disassembly, while 'wet' applications are irreversible. From the analysis of the retrofit system adopted, it is necessary to indicate the weight in $\mathrm{kg}$ for 
each layer/constituent element. The weight $P r_{j}$ of disassemblabled material that can be recycled or reused is then calculated:

$$
P r_{j}=P_{j} \cdot r_{j}
$$

where $P_{j}$ is the weight of the $j$-th material, $r_{j}$ is the percentage of disassemblabled material.

Considering the adopted retrofit system in its entirety, it is possible to define a disassembly indicator expressed by the following equation:

$$
I_{D I S}=\frac{\sum P r_{j}}{P_{t o t}} 100
$$

Regarding the indoor thermal comfort criterion, the main conditioning parameters are surface temperatures, operating temperatures, radiant asymmetry. Since it is not possible to evaluate the thermal comfort conditions considering a single opaque vertical closure, it is however considered possible to associate indicators that offer a relevant contribution. In particular, in winter regime the internal surface temperature of the wall, $T_{\text {sup,int }}$, is assumed as an indicator, whose value must be sufficiently high to obtain a convenient operating temperature limiting the loads of the heating systems. In addition, the internal surface temperature determines the phenomenon of mould formation and/or surface condensation. It should be noted that in the choice of retrofit solutions for existing walls, those with interstitial or surface condensation or mould formation conditions will be automatically excluded following the thermo-hygrometric test. Only if it is possible to solve these problems with appropriate technical measures, will the retrofit alternative be reconsidered for the purposes of the multicriteria comparison.

$$
T_{\text {sup,int }}=T_{i}-R_{S i} \cdot \frac{\dot{Q}}{A}=T_{i}-R_{S i} \cdot U \cdot\left(T_{i}-T_{e}\right)
$$

where:

- $T_{i}$ is the temperature of the indoor environment expressed in ${ }^{\circ} \mathrm{C}$, assumed to be $20^{\circ} \mathrm{C}$;

- $T_{e}$ is the temperature of the external environment expressed in ${ }^{\circ} \mathrm{C}$;

- $R_{S i}$ is the internal surface resistance of the wall expressed in $\mathrm{m}^{2} \mathrm{~K} / \mathrm{W}$ and which in the case of vertical surface and horizontal heat flow takes on a value of 0.13 ;

- $\dot{Q}$ is the thermal flow expressed in $\mathrm{W}$.

To determine the value of the minimum design outdoor temperature, $T_{e}$, reference can be made to UNI 10349 [53].

In summer, it is necessary to control not only overheating due to solar radiation, but also the influence of internal loads (people, appliances, diffuse incoming radiation from transparent surfaces), which is often of great importance in terms of comfort. In this case, it seems appropriate to introduce a further element of evaluation which, as pointed out by Di Perna et al. [54], can be represented by the periodic internal heat capacity $C_{i p}$. This parameter, which is evaluated according to ISO 13786, describes the heat storage capacity on the internal side of a building component and represents the thickness of the internal thermal mass that actually contributes to reducing internal surface temperatures and to lowering the operating temperature in summer.

The Decree 11 October 2017 on CAM establishes that in the case of interventions of new construction and 'major renovation of first level', a periodic internal areic thermal capacity referred to each single opaque structure of the external envelope, calculated according to ISO 13786 , of at least $40 \mathrm{~kJ} / \mathrm{m}^{2} \mathrm{~K}$ must be provided.

For the purposes of indoor comfort, vertical opaque walls also have a significant impact on the control of acoustic comfort, particularly in relation to their ability to limit the transmission of noise between the external and internal environment. In this sense, when comparing individual walls, it is possible to refer to the $R_{W}^{\prime}$ apparent sound insulation index, the calculation procedure for which is given in UNI EN ISO 717-1 [55]. In Italy, 
the current legislative framework on the passive acoustic requirements of buildings is the D.P.C.M. of 5 December 1997 [56], which indicates the limit values of the main acoustic parameters for the different uses of buildings.

Regarding the economic sustainability of the interventions on opaque vertical walls, the total cost is assumed to be the sum of the initial cost and the ordinary and extraordinary maintenance costs over a 30-year period. The initial cost is deduced from the estimated metric calculation with reference to the public works price list of the region where the intervention is located or through a market analysis. Maintenance costs are derived with reference to the operations necessary to maintain full functionality and operability of the analysed building component or its individual parts. The estimation of the maintenance costs is carried out on the basis of the operations planned through a maintenance plan involving the opaque envelope under analysis. For the systems examined, it is possible to refer to the maintenance operations shown in Table 2.

Table 2. Maintenance work planned over a 30-year time horizon.

\begin{tabular}{ccc}
\hline Maintenance Type & Intervention & Time \\
\hline & Surface cleaning & 3 years \\
\cline { 2 - 3 } Ordinary maintenance (M) & $\begin{array}{c}\text { Application of finishes in the } \\
\text { case of microcracks }\end{array}$ & 4 years \\
\cline { 2 - 3 } & $\begin{array}{c}\text { Repair of minor defects } \\
\text { Partial repainting }\end{array}$ & \\
& $\begin{array}{c}\text { Resurfacing (finishing layers) } \\
\text { Restoration of worn parts }\end{array}$ & 7 years \\
\cline { 2 - 3 } & $\begin{array}{c}\text { Restoration or total } \\
\text { renovation of paintwork }\end{array}$ & 10 years \\
\hline $\begin{array}{c}\text { Extraordinary maintenance } \\
\text { (Repl) }\end{array}$ & $\begin{array}{c}\text { Partial replacement (70\%) } \\
\text { ETICS }\end{array}$ & 25 years \\
\hline
\end{tabular}

Maintenance costs are assimilated to expense accounts that occur once at the end of a given year $t$. The discounted value can be calculated as follows:

$$
P V=C_{t} \cdot \frac{1}{(1+d)^{t}}
$$

where:

- $C_{t}$ is the cost of extraordinary maintenance incurred at the end of year $\mathrm{t}$;

- $d$ is the discount rate;

- $t$ is the time interval in years from the start of the analysis to the maintenance date.

It is therefore possible to express the Present Value of the Life Cycle Cost (LCC) using a simplified approach:

$$
L C C=I_{0}+M+R e p l
$$

where:

- $I_{0}$ is the initial investment of the intervention;

- $M$ is the total cost of routine maintenance;

- $\quad R e p l$ is the total cost of extraordinary maintenance.

Table 3 shows a summary scheme of the evaluation criteria and subcriteria adopted with the relative weights and associated indicators. In the absence of specific surveys generally based on consultation of a sample of experts, it has been assumed, as a first approximation, that each criterion and subcriterion has the same weight. By varying the distribution of weights, also in relation to different needs of decision-makers, it is possible, in the future development of this work, to verify the deviation from the hypothesis formulated. 
Table 3. Definition of criteria and subcriteria.

\begin{tabular}{|c|c|c|c|c|c|c|}
\hline $\mathbf{n}$ & Criterion & Relative Weight & & Subcriterion & Relative Weight & Indicator \\
\hline \multirow{2}{*}{$C_{1}$} & \multirow{2}{*}{$\begin{array}{c}\text { Energy } \\
\text { Performance }\end{array}$} & \multirow{2}{*}{0.25} & $C_{1.1}$ & Heat transfer in steady state & 0.5 & $\mathrm{U}\left(\mathrm{W} /\left(\mathrm{m}^{2} \mathrm{~K}\right)\right)$ \\
\hline & & & $C_{1.2}$ & Heat transmission in dynamic state & 0.5 & Yie $\left(\mathrm{W} /\left(\mathrm{m}^{2} \mathrm{~K}\right)\right)$ \\
\hline \multirow{3}{*}{$C_{2}$} & \multirow{3}{*}{$\begin{array}{l}\text { Environmental } \\
\text { Sustainability }\end{array}$} & \multirow{3}{*}{0.25} & $C_{2.1}$ & Recycled/recovered materials & 0.33 & Irec $(\%)$ \\
\hline & & & $C_{2.2}$ & Embodied carbon & 0.33 & $\mathrm{EC}\left(\mathrm{kg} \mathrm{CO}{ }_{2} \mathrm{eq}\right)$ \\
\hline & & & $C_{2.3}$ & Disassembled materials & 0.33 & Idis (\%) \\
\hline \multirow{3}{*}{$C_{3}$} & \multirow{3}{*}{$\begin{array}{l}\text { Indoor } \\
\text { Comfort }\end{array}$} & \multirow{3}{*}{0.25} & $C_{3.1}$ & Internal Surface Temperature & 0.33 & $\mathrm{~T}_{\text {sup,int }}\left({ }^{\circ} \mathrm{C}\right)$ \\
\hline & & & $C_{3.2}$ & Periodic Areic Heat Capacity & 0.33 & $\operatorname{Cip}\left(\mathrm{kJ} /\left(\mathrm{m}^{2} \mathrm{~K}\right)\right)$ \\
\hline & & & $C_{3.3}$ & Apparent soundproofing power & 0.33 & $\mathrm{R}^{\prime} \mathrm{w}(\mathrm{dB})$ \\
\hline$C_{4}$ & $\begin{array}{c}\text { Economic } \\
\text { Sustainability }\end{array}$ & 0.25 & $\begin{array}{l}C_{4.1} \\
\left(A_{n}\right)\end{array}$ & Simplified life cycle cost & 1 & $\mathrm{LCC}=\mathrm{I}_{0}+\mathrm{M}+\operatorname{Repl}(€)$ \\
\hline
\end{tabular}

\subsection{Decision Matrix and Decision Support Index}

Phase 5 of the methodology provides for the assembly of Decision Matrix A (see Table 4), of order $n x m$ (with $n$ number of alternative solutions and $m$ number of judgment criteria) whose generic element $x_{i j}$ represents the value assumed by the $i$-th alternative, $\mathrm{A}_{\mathrm{i}}$, with respect to the $j$-th criterion, $C_{j}$, quantified through the indicators defined in Section 2.1.

Table 4. Decision matrix.

\begin{tabular}{ccccccc}
\hline Intervention & $C_{\mathbf{1}}$ & $C_{\mathbf{2}}$ & $C_{3}$ & $C_{\mathbf{4}}$ & $\ldots$ & $C_{m}$ \\
\hline$A_{\mathbf{1}}$ & $C_{1}\left(A_{1}\right)$ & $C_{2}\left(A_{1}\right)$ & $C_{3}\left(A_{1}\right)$ & $C_{4}\left(A_{1}\right)$ & $\ldots$ & $C_{m}\left(A_{1}\right)$ \\
$A_{\mathbf{2}}$ & $C_{1}\left(A_{2}\right)$ & $C_{2}\left(A_{2}\right)$ & $C_{3}\left(A_{2}\right)$ & $C_{4}\left(A_{2}\right)$ & $\ldots$ & $C_{m}\left(A_{2}\right)$ \\
$A_{3}$ & $C_{1}\left(A_{3}\right)$ & $C_{2}\left(A_{3}\right)$ & $C_{3}\left(A_{3}\right)$ & $C_{4}\left(A_{3}\right)$ & $\ldots$ & $C_{m}\left(A_{3}\right)$ \\
$\ldots$ & $\ldots$ & $\ldots$ & $\ldots$ & $\ldots$ & $\ldots$ & $\ldots$ \\
$A_{\boldsymbol{n}}$ & $C_{1}\left(A_{n}\right)$ & $C_{2}\left(A_{n}\right)$ & $C_{3}\left(A_{n}\right)$ & $C_{4}\left(A_{n}\right)$ & $\ldots$ & $C_{m}\left(A_{n}\right)$ \\
\hline
\end{tabular}

Since the values thus obtained of the matrix are inhomogeneous quantities, it is necessary to proceed to a normalisation of the same, i.e., the values entered must be transformed into dimensionless values between 0 and 1 .

With respect to the evaluation criteria which, in relation to the objectives of the analysis, represent "costs" (criteria $C_{1}, C_{2}$ and $C_{4}$, subcriteria $C_{1.1}, C_{1.2}, C_{2.2}$ and $C_{4.1}$ ) the elements of the matrix can be normalised through Equation (12); if, on the other hand, the criteria represent "benefits" (criteria $C_{2}$ and $C_{3}$, subcriteria $C_{2.1}, C_{2.3}, C_{3.1}, C_{3.2}$, and $C_{3.3}$ ) the elements of the matrix can be normalised with Equation (13). Equations (12) and (13) represent the normalisation method 1 .

- criteria to minimise:

$$
x_{i j}^{\prime}=\frac{x_{j \min }}{x_{i j}}
$$

- criteria to maximise:

$$
x_{i j}^{\prime}=\frac{x_{i j}}{x_{j \max }}
$$

where $x_{j, \min }=\min _{j}\left(x_{i j}\right)$ e $x_{j, \max }=\max _{j}\left(x_{i j}\right)$.

A different system of normalisation, called the normalisation method 2, useful in cases of negative $x_{i j}$ values, is given by the following equations, Equations (14) and (15):

- $\quad$ criteria to minimise:

$$
x_{i j}^{\prime}=\frac{x_{\text {max }}-x_{i j}}{x_{\text {jmax }}-x_{\text {min }}}
$$


- criteria to maximise:

$$
x_{i j}^{\prime}=\frac{x_{i j}-x_{j \min }}{x_{j \max }-x_{j \min }}
$$

where $x_{j, \min }=\min _{j}\left(x_{i j}\right)$ e $x_{j, \max }=\max _{j}\left(x_{i j}\right)$.

Finally, by adopting the SAW technique, Simple Additive Weighting, the following synthetic index of decision support is obtained referring to the generic $i$-th alternative:

$$
I_{D M, i}=\sum_{j} w_{j} x_{i j}^{\prime}
$$

where $w_{j}$ is a coefficient that expresses the relative weight of the $j$-th criterion, the apex indicates the normalised values according to the two previous equations.

This index makes it possible to establish an ordering of alternatives by orienting the choice towards the "optimal" one, i.e., the one which, having a higher index, allows for the best compromise between the various evaluation criteria to be reached.

\section{Implementation of the Methodology to Cases Study}

Using the method described in Section 2, the aim is to obtain a scale of preference among the alternatives submitted for analysis. The alternatives are represented by different insulation materials used for ETICS. The comparison is based on the definition of precise stratigraphies according to the material chosen.

For the application of the decision-making tool to representative case studies, reference was made to specific documents that collect the most common types of building envelope in Europe and, in particular in Italy, within the limits of any regional peculiarities.

A fundamental step, aimed at characterising the stratigraphy of the masonry mainly widespread in Europe, resulted in the technical report UNI/TR 11552 "Abacus of the structures constituting the opaque envelope of buildings". This description is usually used where it is not possible to make precise assessments on the characteristics of the building envelope, based on inspections or other sources. The reference data provide useful information on the methods of isolation used in the various geographic areas based on different historical catalogues.

Focusing on the Italian panorama, through the data deducible from the TABULA (Typology Approach for Building stock energy Assessment) [57] and EPISCOPE (Energy Performance Indicator Tracking Schemes for the Continuous Optimization of Refurbishment Process in European Housing Stocks) projects [58], it was possible to define two stratigraphies characterising the opaque envelope of a typical building. The analysis is based on the examination of the energy, environmental, comfort and economic characteristics, according to the methodology described in Section 2, by examining two samples of external cladding with a unit area of $1 \mathrm{~m}^{2}$. The reference opaque envelope structures are related to the most widespread national building types. The first stratigraphy analysed is based on a hollow-box masonry in perforated bricks with a thickness of $30 \mathrm{~cm}$. In relation to this infill system, the absence of insulating material inside the structure has been assumed, since it was considered a reference period prior to 1976, when the first law was proposed for the containment of thermal energy consumption in buildings (Law 30 March 1976, n. 373) [59]. The package structured in this way determines poor thermal insulation, quantifiable with a thermal transmittance $\mathrm{U}$, equal to $1.11 \mathrm{~W} / \mathrm{m}^{2} \mathrm{~K}$. The second stratigraphy examined is characterised by similar specifications to the first insulation system, having an overall thickness of about $30 \mathrm{~cm}$.

However, depending on the different construction period and the different legal requirements, we opted for the analysis of a system with a medium level of thermal insulation. A construction period after 1991 was assumed, to take into account the regulatory restrictions introduced by Law no. 10 of 1991 [60]. The most common outward-facing insulating stratigraphies in this period have a layer of thermal insulation, generally glass wool, positioned in the cavity. The application of the insulating layer allows for an increase in the thermal insulation of the wall, which can be found through a reduction in thermal 
transmittance, $\mathrm{U}$, up to a value equal to $0.53 \mathrm{~W}\left(\mathrm{~m}^{2} \mathrm{~K}\right)$. Figure 2 shows the two reference stratigraphies mentioned.

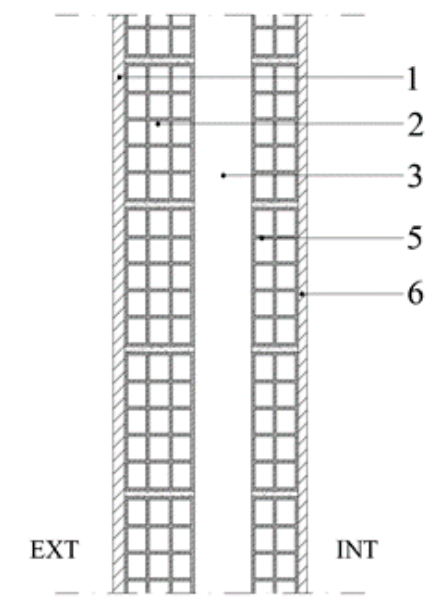

Cavity wall with hollow bricks 1 External plaster depht $20 \mathrm{~mm}$ 2 Hollow brick $12 \times 24 \times 24$

3 Air cavity depht $100 \mathrm{~mm}$

4 Hollow brick $8 \times 24 \times 24$

5 Internal plaster depth $2.0 \mathrm{~cm}$

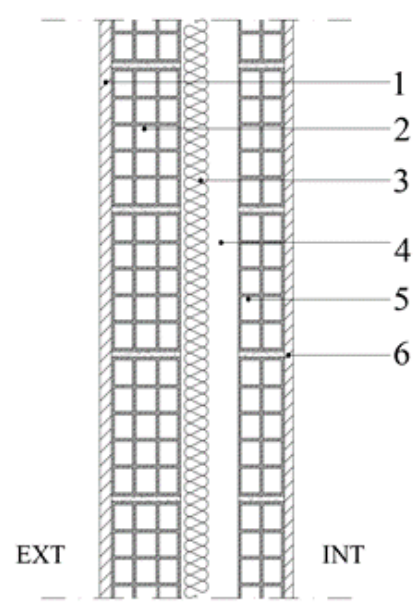

Cavity wall with hollow bricks and cavity insulation 1 External plaster depht $20 \mathrm{~mm}$

2 Hollow brick $12 \times 24 \times 24$

3 Fiberglass insulation depth $5.0 \mathrm{~cm}$

4 Air cavity depht $100 \mathrm{~mm}$

5 Hollow brick $8 \times 24 \times 24$

6 Internal plaster depth $2.0 \mathrm{~cm}$

Figure 2. Reference walls considered.

The Italian climatic zones, defined according to the DPR n. 412/1993 [61], as shown in Figure 3, the most widespread, by number of municipalities falling within them and by territorial extension, are zone C (from 900 to 1400 degrees day), zone D (from 1401 to 2100 degrees day) and zone E (from 2101 to 3000 degree days); the latter in particular affects about $53 \%$ of Italian municipalities.
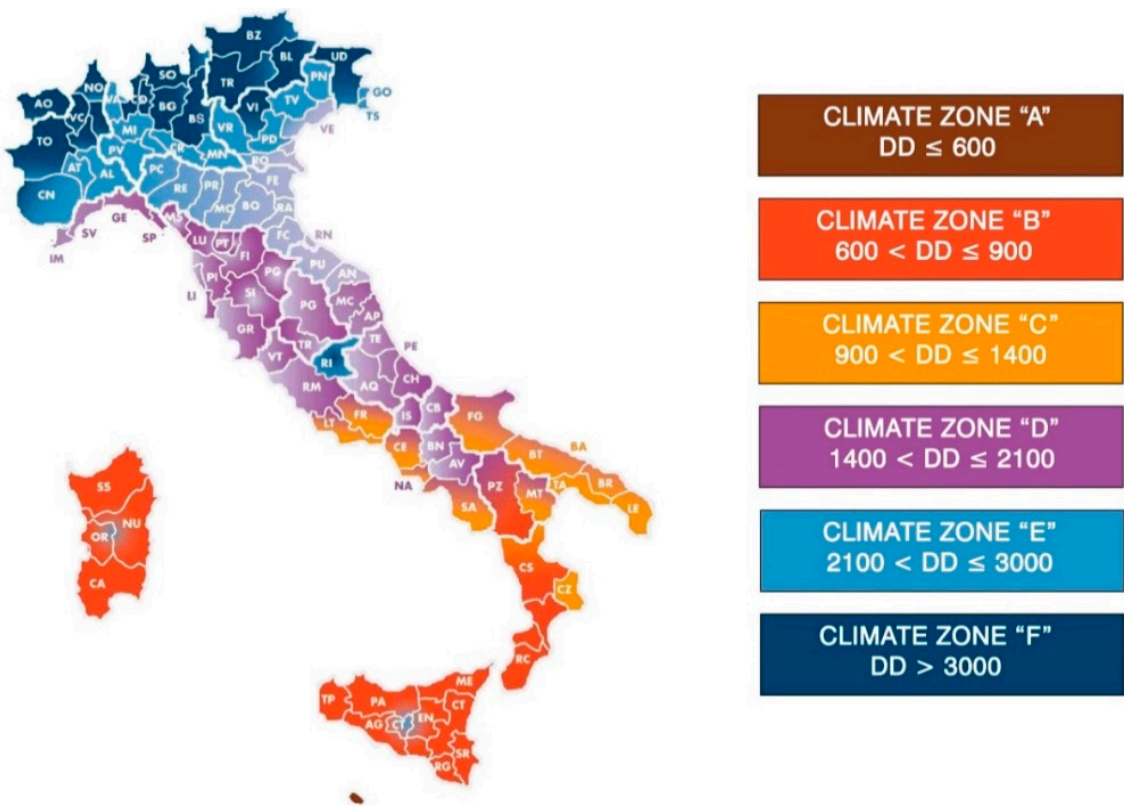

Figure 3. Subdivision of the Italian territory into climatic zones based on degree day.

The design of the external insulation system relating to the reference stratigraphies can be traced back to "energy requalification" interventions as defined by the Decree of 26 June 2015. Depending on the climatic zones C, D and E, it is possible to define the characteristics, in terms of thickness and thermophysical properties, afferent to the layer of 
insulation to be used in the building system. In particular, between one alternative and the other, the transmittance values differ slightly as the smallest commercial thickness has been determined that meets the regulatory limits of transmittance (see Figure 4).

EXT

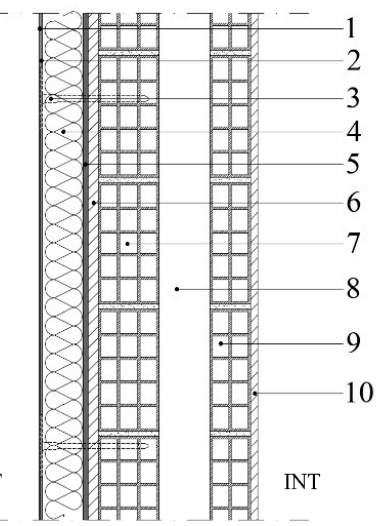

Cavity wall with hollow bricks and ETICS

1 External decorative finish and primer depth $2.5 \mathrm{~mm}$

2 Adhesive render coat with glass fibre reinforcement

meshcloth depth $4.0 \mathrm{~mm}$

3 Fixings to accomodate all insulant thiknesses

4 Insulation board with different thicknesses

5 Adhesive render coat depht $10 \mathrm{~mm}$

6 External plaster depht $20 \mathrm{~mm}$

7 Hollow brick $12 \times 24 \times 24$

8 Air cavity depht $100 \mathrm{~mm}$

9 Hollow brick $8 \times 24 \times 24$

10 Internal plaster depth $2.0 \mathrm{~cm}$

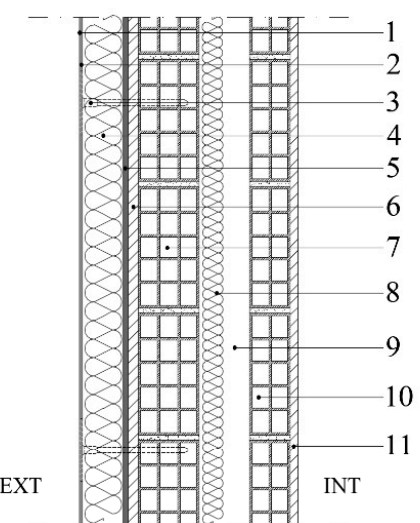

Cavity wall with hollow bricks, cavity insulation and

ETICS

1 External decorative finish and primer depth $2.5 \mathrm{~mm}$

2 Adhesive render coat with glass fibre reinforcement meshcloth depth $4.0 \mathrm{~mm}$

3 Fixings to accomodate all insulant thiknesses

4 Insulation board with different thicknesses

5 Adhesive render coat depht $10 \mathrm{~mm}$

6 External plaster depht $20 \mathrm{~mm}$

7 Hollow brick $12 \times 24 \times 24$

8 Fiberglass insulation depth $5 \mathrm{~cm}$

9 Air cavity depht $100 \mathrm{~mm}$

10 Hollow brick $8 \times 24 \times 24$

11 Internal plaster depth $2.0 \mathrm{~cm}$

Figure 4. Reference walls insulated using ETICS (External Thermal Insulation Composite System).

As specified in Section 2, the analysis method makes it possible to compare different project alternatives, based on the indicators relating to four evaluation criteria and related subcriteria. The evaluation and comparison of the different materials used in the insulation systems were carried out on the basis of two different procedures: first of all, a four-criteria model was prepared which is based on energy, environmental, comfort and economic criteria. Each criterion was divided into several subcriteria which were assessed on the basis of objective indicators (Table 4).

A second procedure, entirely similar to the first one, is based on the comparison of the materials to be used for the insulation systems on the basis of a three-criteria model. This procedure, based on the use of three criteria rather than four, derives from the merger of the energy and environmental criteria into a single evaluation criterion. Both the first and the second process are based on an identical criteria-weighing mechanism: each criterion receives the same importance through the attribution of an equivalent percentage rate; each subcriterion is weighted so that the sum of their percentage weights, if related to a similar criterion, is unitary. The criteria chosen explicitly refer to the three spheres of sustainability.

By way of example, the matrix of decisions relating to the "climate zone E-Milan", compiled with the values of the various indicators, is shown in Table 4 . Below we move on to the matrix normalisation phase, shown in Table 5. The alternatives of insulating materials are as follows: 1. Rock wool (RW), 2. Sintered Expanded Polystyrene (EPS), 3. EPS with graphite (EPS + G), 4. Extruded Expanded Polystyrene (XPS), 5. Polyurethane (PUR), 6. Wood fiber (WF), 7. Cork (CK), 8. Airgel (AG), 9. Vacuum insulation panels (VIPs), 10. Calcium Hydrate Silicate (CSH). In the present study, it was decided to use both the standardisation techniques described in Section 2; in particular in the context of normalisation 1 (refer to Equations (9) and (10)), the negative values of the "EC" subcriterion were transformed into values relatively close to 0 to avoid problems of inapplicability from an algebraic point of view. 
Table 5. Compilation of the decision matrix.

\begin{tabular}{|c|c|c|c|c|c|c|c|c|c|}
\hline \multirow{3}{*}{ ETICS } & \multicolumn{9}{|c|}{ Criteria } \\
\hline & \multicolumn{2}{|c|}{ Energy Performance } & \multicolumn{3}{|c|}{$\begin{array}{l}\text { Environmental } \\
\text { Sustainability }\end{array}$} & \multicolumn{3}{|c|}{ Indoor Comfort } & \multirow{2}{*}{$\begin{array}{c}\text { Economic } \\
\text { Sustainability } \\
L C C\end{array}$} \\
\hline & $u$ & $Y_{I E}$ & $I_{\text {rec }}$ & $E C$ & $I_{d i s}$ & $T_{\text {sup,int }}$ & $C_{i p}$ & $R^{\prime} w$ & \\
\hline RW & 0.269 & 0.027 & 37.00 & 0.06 & 13.209 & 19.126 & 48.98 & 47.10 & 312.47 \\
\hline EPS & 0.278 & 0.029 & 10.00 & 2.77 & 4.366 & 19.097 & 49.02 & 46.89 & 310.24 \\
\hline $\mathrm{EPS}+\mathrm{G}$ & 0.274 & 0.028 & 10.00 & 14.11 & 4.366 & 19.110 & 49.01 & 46.89 & 302.78 \\
\hline XPS & 0.273 & 0.028 & 5.00 & 0.48 & 7.507 & 19.113 & 49.00 & 46.93 & 302.78 \\
\hline PUR & 0.267 & 0.027 & 2.57 & 0.43 & 4.250 & 19.132 & 49.00 & 46.89 & 337.77 \\
\hline WF & 0.271 & 0.021 & 98.00 & -13.85 & 31.820 & 19.119 & 48.75 & 48.00 & 329.52 \\
\hline CK & 0.267 & 0.025 & 99.00 & -13.86 & 16.340 & 19.132 & 48.90 & 47.29 & 429.24 \\
\hline AG & 0.253 & 0.024 & 60.00 & 0.37 & 10.245 & 19.178 & 48.94 & 47.07 & 958.41 \\
\hline VIPs & 0.225 & 0.020 & 10.00 & 0.42 & 4.828 & 19.269 & 48.90 & 46.90 & 473.28 \\
\hline $\mathrm{CSH}$ & 0.268 & 0.026 & 17.00 & 7.87 & 18.920 & 19.129 & 48.95 & 47.39 & 348.99 \\
\hline
\end{tabular}

Then we move on to the matrix normalisation phase. In the present study, it was decided to use both standardisation techniques described in Section 3. According to normalisation method 1 , the values in the first column of Table 5, related to the subcriterion $\mathrm{U}$ to be minimised, Equation (12) should be used. Accordingly, each value given in the first column of Table 5 is to be divided by the minimum value of the calculated U. For example, once identified the minimum value of column $\mathrm{U}$, equal to 0.225 , it is possible to normalise the value related to RW through Equation (12):

Value to minimize:

$$
\frac{0.225}{0.269}=0.836
$$

At the same time, in the case of a criterion to be maximised, such as $\mathrm{I}_{\mathrm{rec}}$, each element of the second column of Table 5, must be divided by the maximum value found in the same column. For example, once the maximum value of column $\mathrm{I}_{\text {rec }}$ is identified, equal to 99.00 , it is possible to normalise the value related to RW through Equation (13):

Value to maximise:

$$
\frac{37.00}{99.00}=0.374
$$

A similar process is followed for normalisation method 2. In this case, rather than employing Equations (12) and (13), Equations (14) and (15) will be applied.

In the context of normalisation method 1, the negative values of the "EC" subcriterion were transformed into values relatively close to 0 to avoid problems of algebraic inapplicability. These values are negative as they refer only to the production phase (from cradle to gate) and not to the whole life cycle balance (from cradle to grave). Table 6 shows the results of normalisation method 1. 
Table 6. Normalisation of the decision matrix.

\begin{tabular}{|c|c|c|c|c|c|c|c|c|c|}
\hline \multirow{3}{*}{ ETICS } & \multicolumn{9}{|c|}{ Criterion } \\
\hline & \multicolumn{2}{|c|}{ Energy } & \multicolumn{3}{|c|}{ Environment } & \multicolumn{3}{|c|}{ Comfort } & \multirow{2}{*}{$\begin{array}{c}\begin{array}{c}\text { Economic } \\
\text { Sustainability }\end{array} \\
L C C\end{array}$} \\
\hline & $u$ & $Y_{I E}$ & $I_{\text {rec }}$ & $E C$ & $I_{d i s}$ & $T_{\text {sup,int }}$ & $C_{i p}$ & $R^{\prime} w$ & \\
\hline RW & 0.836 & 0.741 & 0.374 & 0.167 & 0.415 & 0.993 & 0.999 & 0.981 & 0.969 \\
\hline EPS & 0.809 & 0.690 & 0.101 & 0.004 & 0.137 & 0.991 & 1.000 & 0.977 & 0.976 \\
\hline $\mathrm{EPS}+\mathrm{G}$ & 0.821 & 0.714 & 0.101 & 0.001 & 0.137 & 0.992 & 1.000 & 0.977 & 1.000 \\
\hline XPS & 0.824 & 0.714 & 0.051 & 0.021 & 0.236 & 0.992 & 1.000 & 0.978 & 1.000 \\
\hline PUR & 0.843 & 0.741 & 0.026 & 0.023 & 0.134 & 0.993 & 1.000 & 0.977 & 0.896 \\
\hline WF & 0.830 & 0.952 & 0.990 & 1.000 & 1.000 & 0.992 & 0.994 & 1.000 & 0.919 \\
\hline CK & 0.843 & 0.800 & 1.000 & 1.000 & 0.513 & 0.993 & 0.998 & 0.985 & 0.705 \\
\hline AG & 0.889 & 0.833 & 0.606 & 0.027 & 0.322 & 0.995 & 0.998 & 0.981 & 0.316 \\
\hline VIPs & 1.000 & 1.000 & 0.101 & 0.024 & 0.152 & 1.000 & 0.998 & 0.977 & 0.640 \\
\hline $\mathrm{CSH}$ & 0.840 & 0.769 & 0.172 & 0.001 & 0.595 & 0.993 & 0.999 & 0.987 & 0.868 \\
\hline
\end{tabular}

\section{Results and Discussion}

From the application of the methodology to the case studies, it emerged that:

- the ETICS alternative that achieves the best compromise between the different evaluation criteria, both in the 3-criteria model and in the 4-criteria one, and with the normalisation methods 1 and 2, is the one with a wood fibre insulating panel; this alternative is confirmed as the best also in the different three climatic zones considered (Figure 5);

- in relation to the two reference stratigraphies, the "optimal" alternative is always the "WF" (Figure 6);

- in most simulations, the second "optimal" system is the one that provides for insulation with cork (Figure 6 and Figure 9);

- the ETICS alternative with rock wool generally occupies the third position in the preferential ordering of alternatives (Figure 5, Figure 6 and Figure 9). 

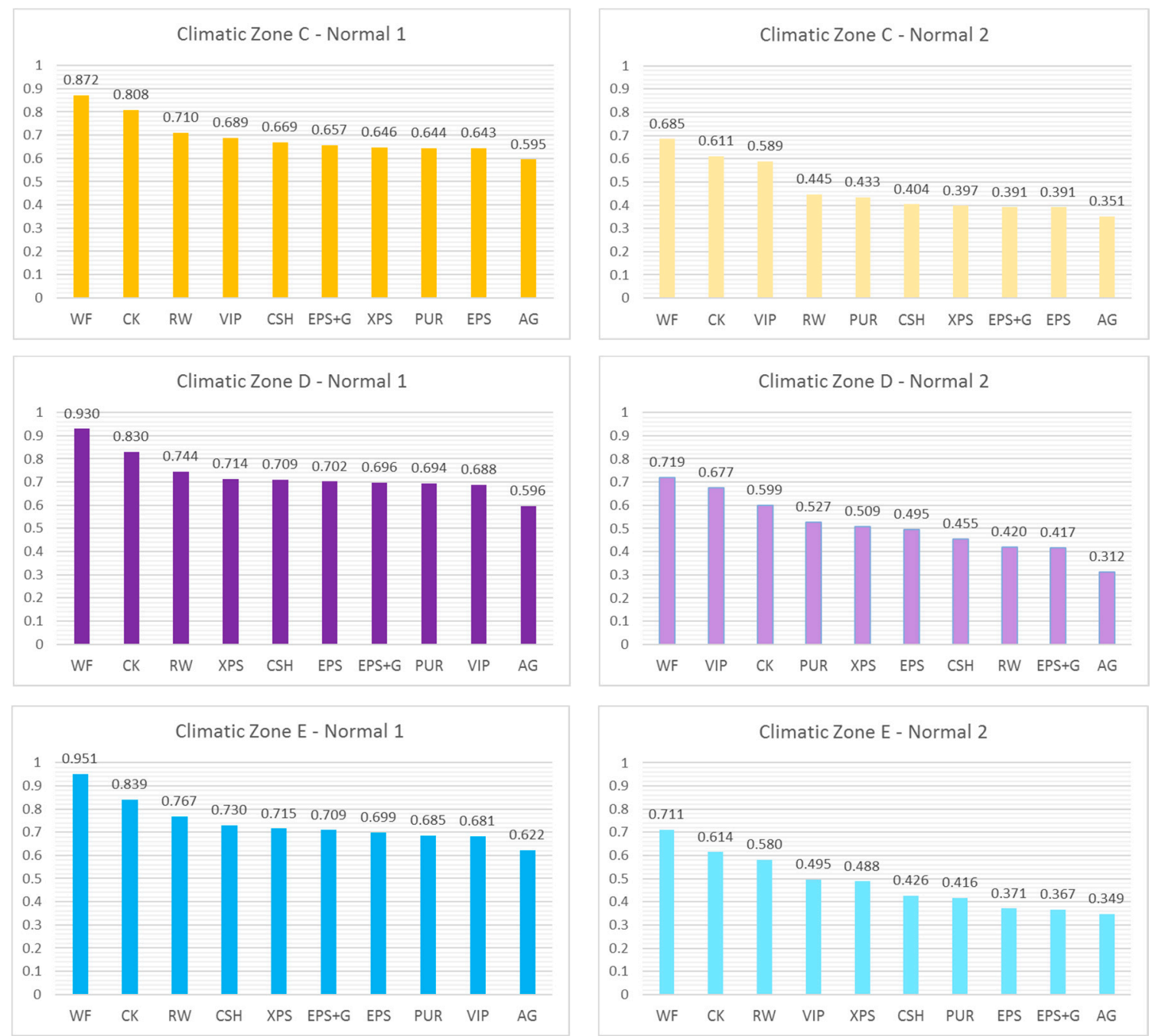

Figure 5. Sorting of the ETICS alternatives in the three climatic zones and according to the two normalisation methods.
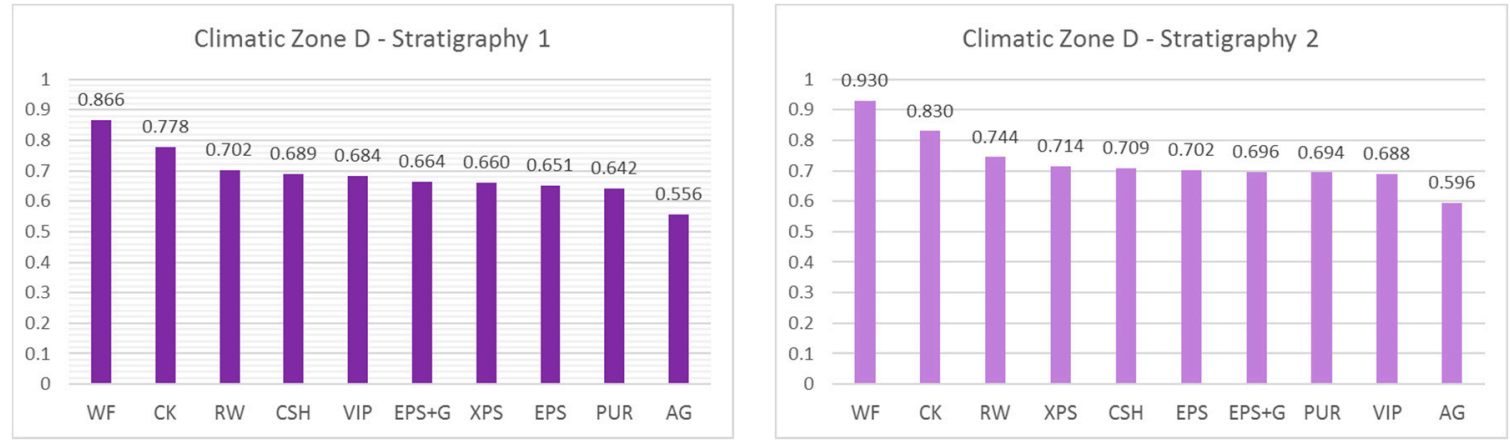

Figure 6. Ordering of alternatives with reference to climatic zone D and the two existing walls considered.

On the basis of the results obtained, it is possible to represent in a Kiviat diagram the various ETICS alternatives according to the nine subcriteria adopted (Figure 7). In this way, it is possible to compare the performance level of the $i$-th alternative with respect to the single subcriterion and to have a representation of the global distribution of the $i$-th alternative with respect to all the subcriteria. The area of the polygon drawn for each alternative will reach a greater extent, depending on a greater compliance with the analysis criteria. 


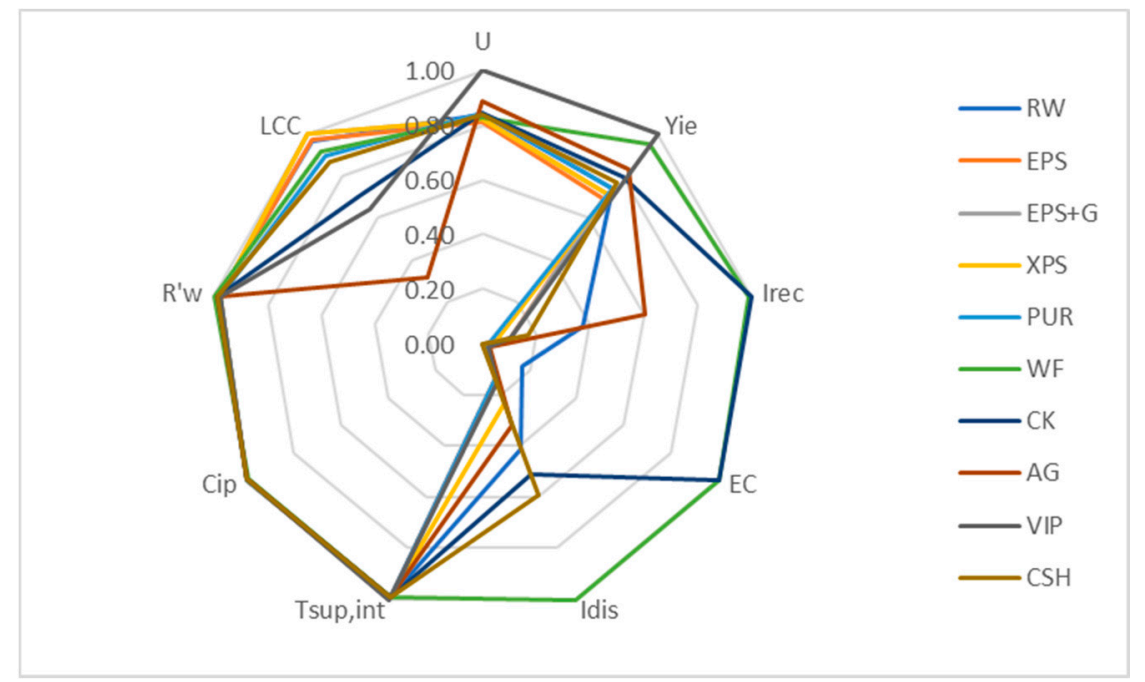

Figure 7. The Kiviat diagram of the alternative ETICS with respect to the nine subcriteria.

This representation is still useful if intending to further the comparison between specific alternatives: for example, it is possible to represent the alternatives that achieve the highest score globally or with respect to a single subcriterion. The graph shown in Figure 8 highlights how the use of an innovative material, namely the VIPs (Vacuum Insulation Panels), although it is performing from an energy and comfort point of view, fails to satisfy the indicators relating to the disassembly index, $\mathrm{I}_{\mathrm{dis}}$, the recoverability index, $\mathrm{I}_{\mathrm{rec}}$, and the simplified cost of the LCC life cycle.

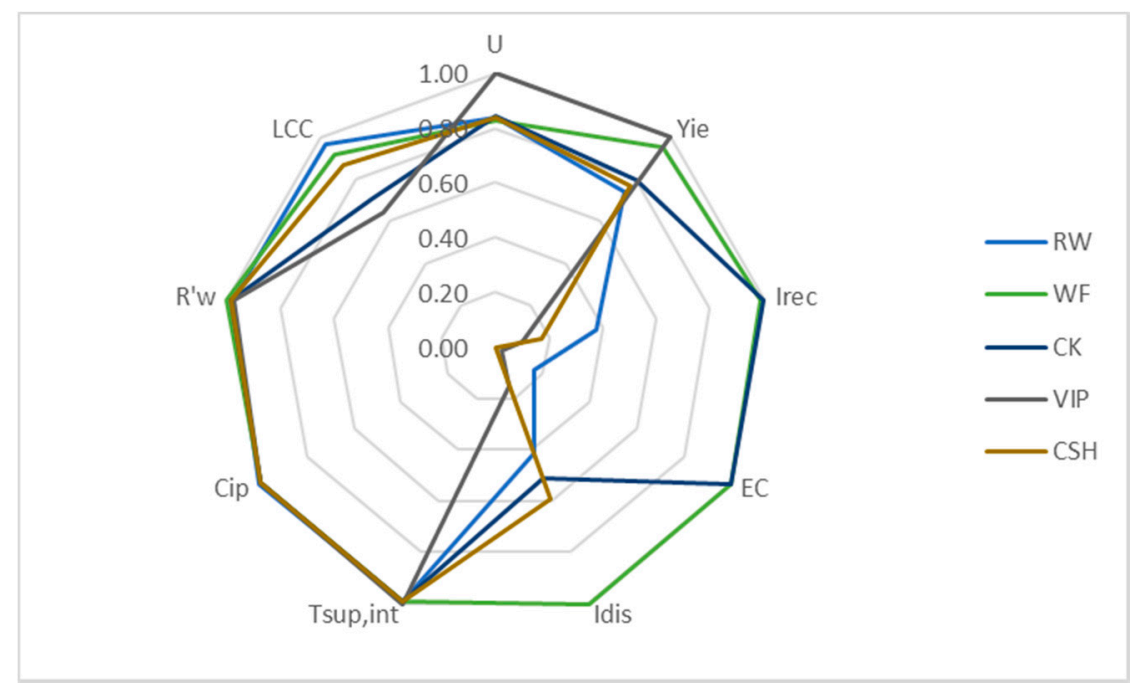

Figure 8. Analysis through the Kiviat diagram of five alternative ETICS.

Wood fiber and cork, on the other hand, are materials of vegetable origin with a very reduced environmental impact in the life cycle. Even rock wool, an insulator of mineral origin, has a low environmental impact. Wood fibre and rock wool also show a slightly higher economic sustainability profile than cork (Figure 9 and Figure 11). 


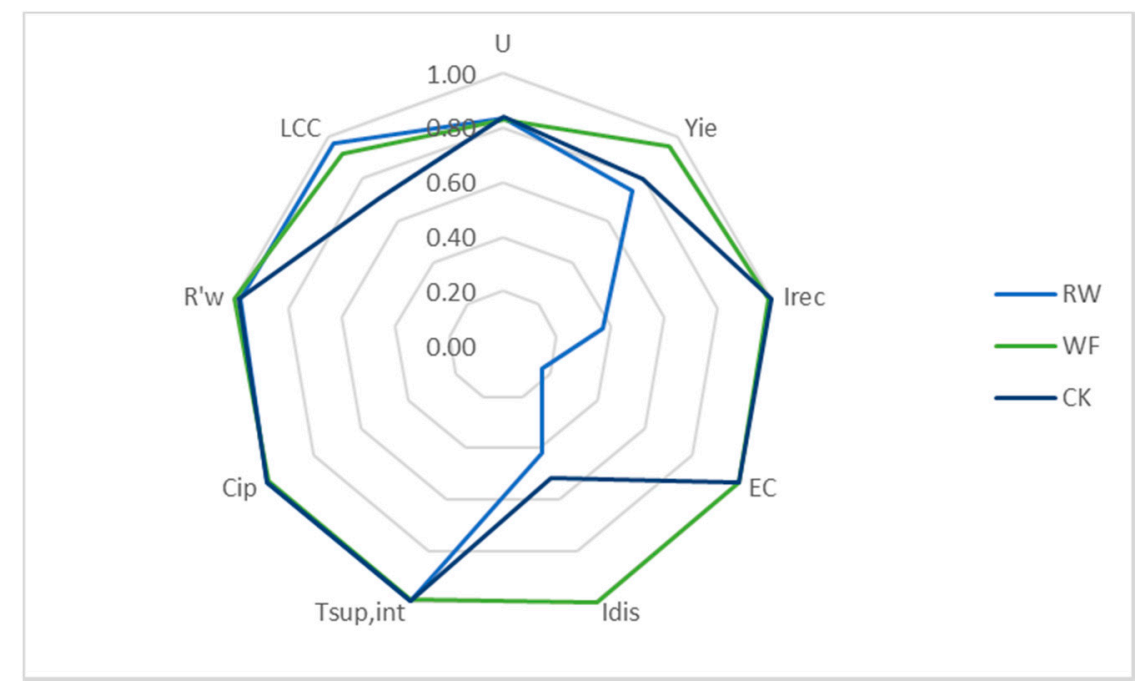

Figure 9. The Kiviat diagram of the three best ETICS alternatives.

From the point of view of comfort and energy performance, wood fibre, despite having a higher thermal conductivity than other synthetic insulators such as polyurethane or innovative insulating materials (Airgel, VIPs, etc.), is a bulk material which therefore gives excellent properties on the walls in terms of phase shift and thermal attenuation in summer.

The results obtained also show the "robustness" of the methodology which, upon varying some parameters such as the type of normalisation and the grouping of the criteria (and relative weights), returns a sufficiently stable ordering of alternatives (Figures 5 and 10), in any case, useful to orient the decision maker towards those alternatives that best respond to a logic of sustainability understood in its three conventional areas, environmental, social and economic. It is specified that the attribution of the relative weights took place with a view to a perfect balance between the various criteria and subcriteria. In particular, with the three-criteria model, it was intended to favour those interventions consistent with the triple declination of the concept of sustainability. Nonetheless, in relation to a different framework of decision-makers' needs, it is possible to vary the relative weights to attribute greater importance to certain aspects that better respond to the set objectives.

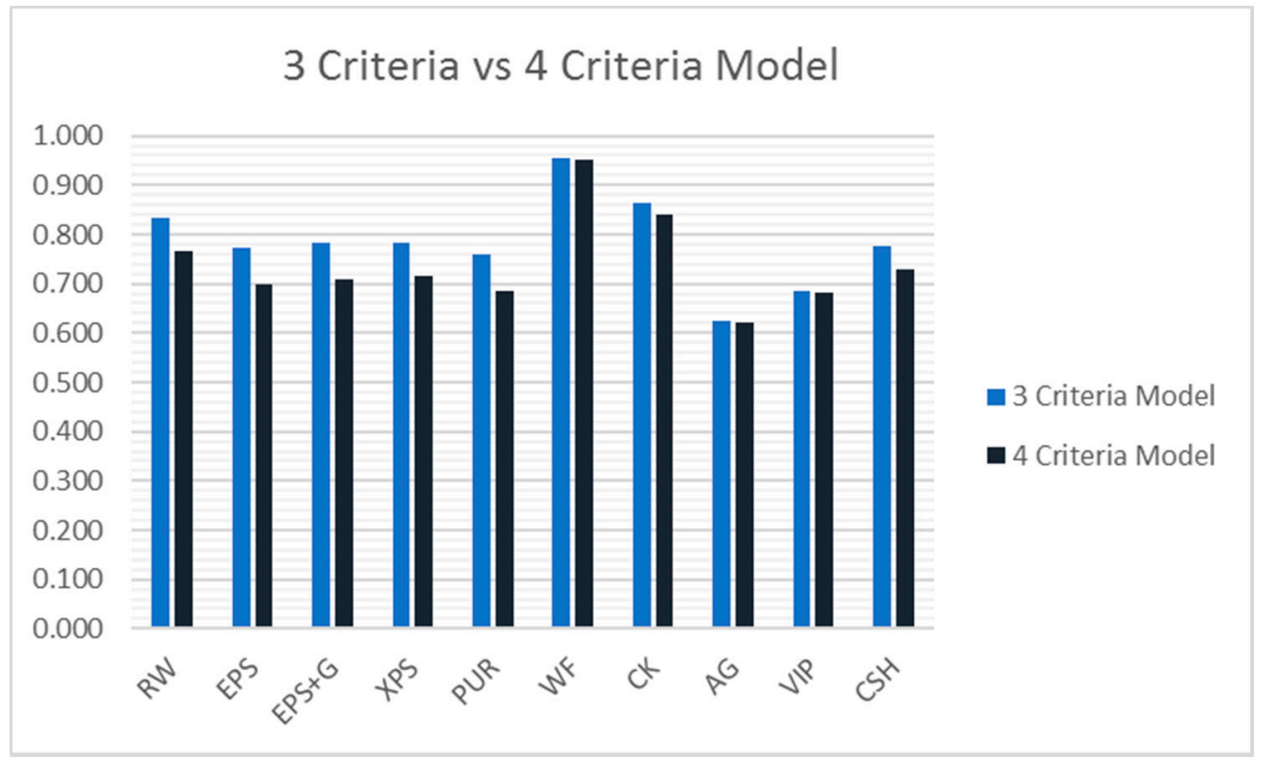

Figure 10. Comparison between alternative sorting in 3- and 4-criteria models. 
The VIPs together with the Aerogel exhibit exceptional energy performance, especially when compared to the very reduced thickness (in particular the VIPs) of the insulation panels being analysed, but still have very high costs and are therefore penalised in terms of economic sustainability. Airgels have very high costs compared to all other ETICS and therefore almost always occupy the last position of the preferential order. Specifically, the graph shown in Figure 11 highlights the behaviour of the materials used in insulation systems from the outside as a function of the stationary thermal transmittance and the cost of the intervention and its maintenance.

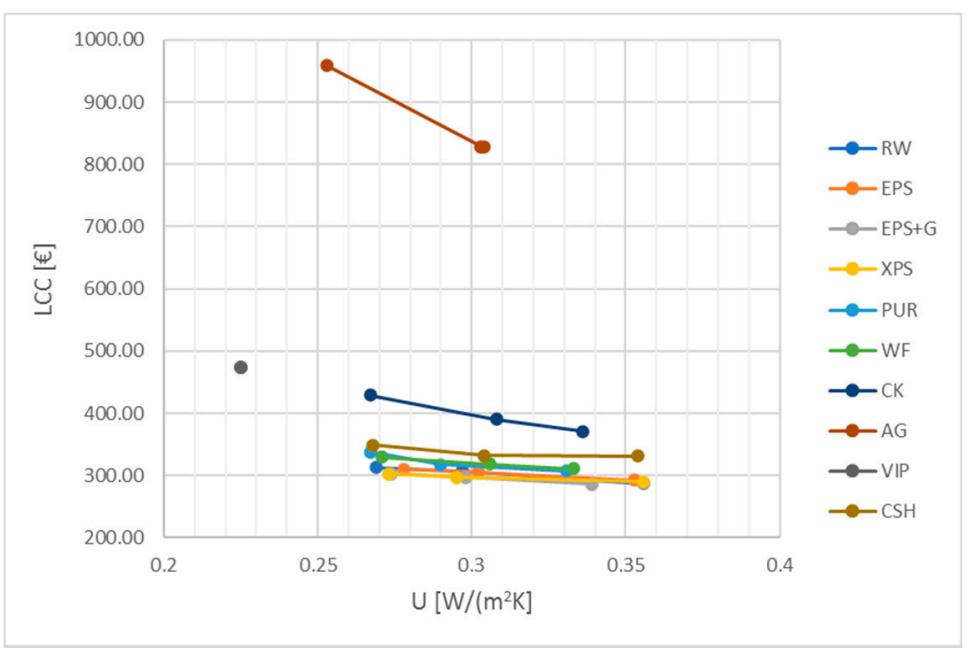

Figure 11. Life Cycle Cost (LCC) values as a function of $U$ transmittance.

In conclusion, in order to summarise the information that can be deduced from the different applications of the method, it is possible to refer to the representation of Figure 12. This graph shows the variability range of the decision support index centred on the midpoint, whose data refer to the area climatic $\mathrm{E}$ and derive from the two standardisation procedures and the two 3- and 4-criteria models. It is confirmed that, in the climatic zone E with the greatest number of municipalities, wood fibre has a limited range of variability with a midpoint above the averages of the other materials. Similarly, the ETICS made with cork has an equally limited range of variability in the decision support index with an average value that ranks second after the wood fibre. It is observed that the VIPs have the lowest min-max variability range, but this is due to the ability of this material to meet the transmittance limits in the various climatic zones, always with the same thickness $(10 \mathrm{~mm})$. The small variation of the support index is exclusively linked to the different normalisation procedures used as well as the two different multicriteria models. 


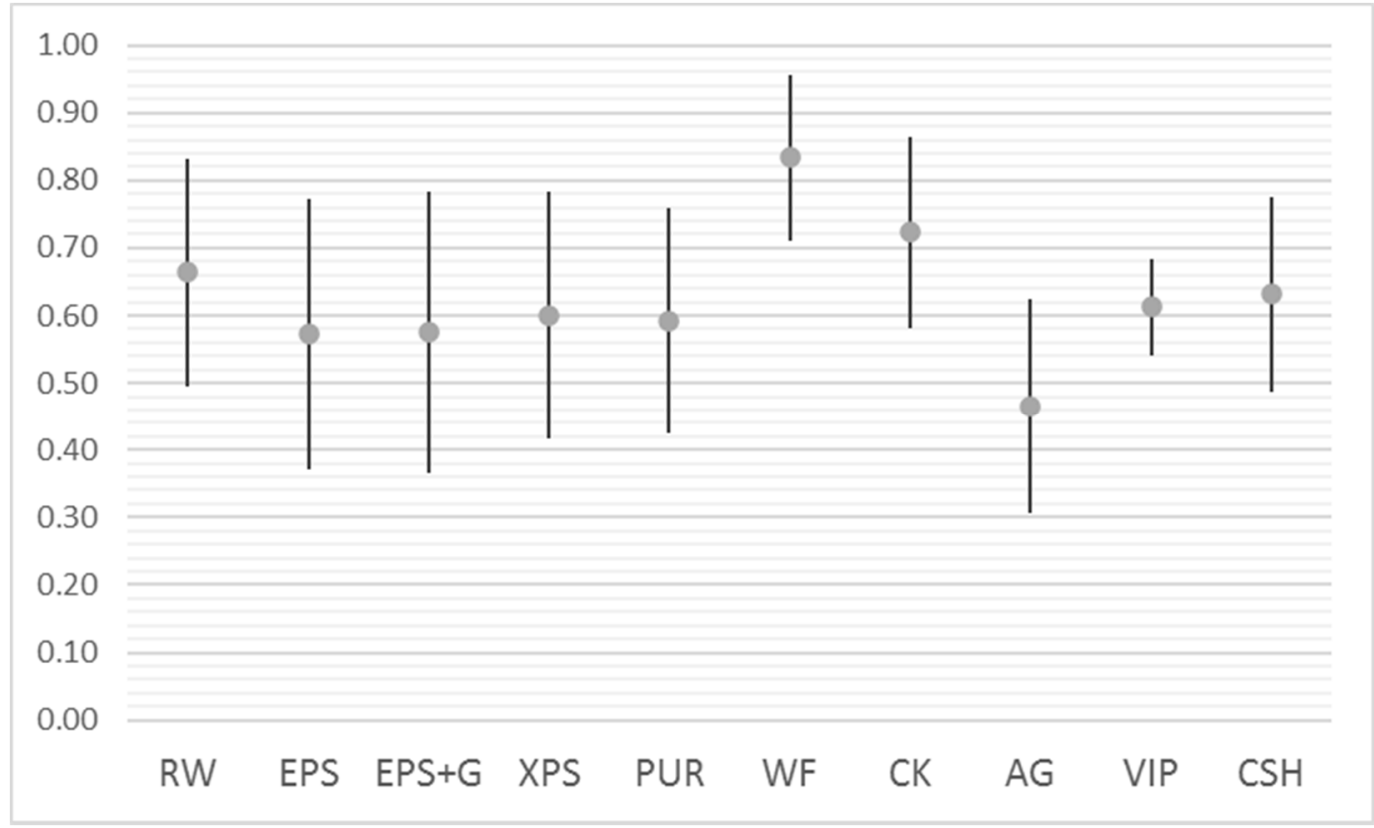

Figure 12. Variability considering the mean value of the score of the alternatives (climatic zone E).

\section{Conclusions}

Facades, being generally the largest component of the building, play a key role in reducing energy consumption.

The proposed methodological tool is useful for choosing the retrofit interventions of the walls of the building envelope that best meet the criteria of energy-environmental sustainability, comfort (social sustainability) during the design phase of a new building or energy requalification of an existing building and economic sustainability. Furthermore, this tool can also be used by Public Administrations in the drafting of public works tenders to be awarded through multicriteria methodologies.

Two models have been implemented, a first with four criteria (energy, environment, comfort and economy) and a second with three criteria, combining energy and environment in a single criterion. In order to give the same importance to each criterion and subcriterion, equal relative weights were attributed in this contribution for each hierarchical level, simulating the point of view of a decision maker who intends to give the same weight to the three areas into which the sustainability concept. However, in relation to a different requirement framework, for example to a decision maker who intends to give greater importance to environmental impacts, it is always possible to change the vector of relative weights, which is an expression of different points of view based on varying needs and objectives.

The methodology was applied to two case studies corresponding to the two most widespread stratigraphies in Italy, before 1991 (significant year for the introduction of Law 10 of 1991) and later, in the three climatic zones, C, D and E, which group together the largest number of municipalities and cover the largest national territorial extension. From the processing carried out, it emerged that the optimal alternative is ETICS with wood fibre. This material, of natural origin, despite having a lower thermal conductivity than synthetic materials (polyurethane, EPS, EPS with graphite) and other innovative materials, exhibits the best compromise overall compared to the various criteria and subcriteria. From an environmental point of view, wood fibre, as well as cork, have the lowest impacts.

This tool is part of the multicriteria decision support methods that are useful for guiding decision makers in comparisons with a sufficiently high number of variables. The proposed tool is aimed at evaluating 10 ETICS, characterised by 10 different insulation materials. The choice to consider a system of external insulation is motivated by the greater diffusion of this insulation technique, not only on a national scale. The wide spread of this 
system is due to the higher efficiency in terms of energy saving compared to other insulation techniques as highlighted in Section 1. However, implementations can be envisioned for the proposed tool. For instance, an easy development process may be the introduction of new criteria and subcriteria for the evaluation of different aspects compared to the ones already analysed.

A further development will make it possible to compare different thermal insulation techniques of building facades beyond ETICS, such as ventilated walls, overcladding systems, green facades. Therefore, besides defining the insulation material capable of identifying the best compromise between the criteria used in the evaluation process, the performance, technical and economic aspects of some of the main building insulation systems will be defined.

Author Contributions: Conceptualisation, P.F. and G.D.; methodology, P.F., G.D. and C.F.; validation, P.F. and G.D.; formal analysis, P.F., G.D. and C.F.; investigation, P.F., G.D. and C.F.; data curation, G.D. and C.F.; writing-original draft preparation, G.D. and C.F.; writing-review and editing, P.F., G.D. and C.F.; supervision, P.F. All authors have read and agreed to the published version of the manuscript.

Funding: This research received no external funding.

Institutional Review Board Statement: Not applicable.

Informed Consent Statement: Not applicable.

Data Availability Statement: We do not have a data archive to disseminate.

Conflicts of Interest: The authors declare no conflict of interest.

\section{References}

1. Hegger, M.; Fuchs, M.; Stark, T.; Zeumer, M. Energy Manual: Sustainable Architecture, Birkhäuser, 1st ed.; Walter de Gruyter: Berlin, Germany, 2008.

2. United Nations Environment Programme UNEP. Building and Climate Change: Summary of Desicion-Makers; United Nations Environment Programme UNEP: Paris, France, 2009; p. 62.

3. Assembly, G. Resolution Adopted by the General Assembly on 25 September 2015, Transforming Our World: The 2030 Agenda for Sustainable Development; UN General Assembly: New York, NY, USA, 2015.

4. Energy Performance of Buildings Directive, European Commission, Energy Efficiency. Available online: https://ec.europa. eu/energy/topics/energy-efficiency/energy-efficient-buildings/energy-performance-buildings-directive_en (accessed on 26 November 2020).

5. Eurostat, Waste Generation by Economic Activities and Households, EU-28. 2016. Available online: https://ec.europa.eu/ eurostat/statistics-explained/index.php?title=File:Waste_generation_by_economic_activities_and_households,EU-28,_2016 _(\%25).png (accessed on 26 November 2020).

6. Communication from the Commission to the European Parliament, the European Council, the Council, the European Economic and Social Committee and the Committee of the Regions, Brussels, Belgium. 2019. Available online: https://eur-lex.europa.eu/ resource.html?uri=cellar:b828d165-1c22-11ea-8c1f-01aa75ed71a1.0002.02/DOC_1\&format=PDF (accessed on 28 November 2020).

7. The European Green Deal A European Green Deal, Striving to Be the First Climate-Neutral Continent. Available online: https: / / ec.europa.eu/info/strategy/priorities-2019-2024/european-green-deal_en (accessed on 28 November 2020).

8. Directive 2010/31/EU of the European Parliament and of the Council of 19 May 2010 on the Energy Performance of Buildings, Brussels, Belgium. 2010. Available online: https://eur-lex.europa.eu/legal-content/EN/TXT/?uri=celex\%3A32010L0031 (accessed on 2 November 2020).

9. Directive 2012/27/EU of the European Parliament and of the Council of 25 October 2012 on Energy Efficiency, Amending Directives 2009/125/EC and 2010/30/EU and Repealing Directives 2004/8/EC and 2006/32/EC; EU: Brussels, Belgium, 2012.

10. Directive (EU) 2018/844 of the European Parliament and of the Council of 30 May 2018 Amending Directive 2010/31/EU on the Energy Performance of Buildings and Directive 2012/27/EU on Energy Efficiency; EU: Brussels, Belgium, 2018.

11. Commission Recommendation (EU) 2019/786 of 8 May 2019 on Building Renovation (Notified under Document c(2019) 3352); Commission Recommendation (EU): Brussels, Belgium, 2019.

12. Commission Recommendation (EU) 2019/1019 of 7 June 2019 on Building Modernization; Commission Recommendation (EU): Brussels, Belgium, 2019.

13. Boriani, A.; Cariani, W.; Romani, R. Guida Pratica Alla Ristrutturazione e Riqualificazione Energetica Degli Edifici, 1st ed.; ENEAAgenzia Nazionale Efficienza Energetica: Rome, Italy, 2020; Available online: http://data.europa.eu/eli/dir/2018/844/oj (accessed on 28 November 2020). 
14. Ministero dello Sviluppo Economico, Ministero delle Infrastrutture e dei Trasporti, Piano Nazionale Integrato per l'Energia e il Clima. Available online: https://www.mise.gov.it/images/stories/documenti/PNIEC_finale_17012020.pdf (accessed on 28 November 2020).

15. Regulation (EU) 2018/1999 of the European Parliament and of the Council of 11 December 2018 on the Governance of the Energy Union and Climate Action. 2018. Available online: https:/ / eur-lex.europa.eu/legal-content/IT/TXT/PDF/?uri=CELEX: 32018R1999\&from $=E N$ (accessed on 28 November 2020).

16. Legge 27 dicembre 1997, n. 449. Misure Per la Stabilizzazione Della Finanza Pubblica; Pubblicata su Gazzetta Ufficiale Serie Generale n.22 del 28-01-1998-Suppl. Ordinario n. 19; Ministero dell'Economia e delle Finanze: Rome, Italy, 1997.

17. Legge 27 Dicembre 2006, n. 296. Disposizioni Per la Formazione del Bilancio Annuale e Pluriennale Dello Stato (Legge Finanziaria 2007); Pubblicata su Gazzetta Ufficiale Serie Generale n. 299 del 27 dicembre 2006-Suppl. Ordinario n. 244; Ministero dell'Economia e delle Finanze: Rome, Italy, 2006.

18. Decreto-Legge del 04/06/2013 n. 63. Disposizioni Urgenti per il Recepimento Della Direttiva 2010/31/UE del Parlamento Europeo e del Consiglio del 19 Maggio 2010, Sulla Prestazione Energetica Nell'edilizia per la Definizione delle Procedure D'infrazione Avviate Dalla Commissione Europea, Nonche' altre Disposizioni in Materia di Coesione Sociale, Pubblicato su Gazzetta Ufficiale Serie Generale n. 130 del 5 giugno 2013; Presidente Della Repubblica: Rome, Italy, 2013.

19. Legge 27 dicembre 2019, n. 160. Bilancio di Previsione dello Stato per L'anno Finanziario 2020 e Bilancio Pluriennale per il Triennio 2020-2022, Pubblicato su Gazzetta Ufficiale Serie Generale n.304 del 30-12-2019—Suppl. Ordinario n. 45L. 160/2019; Presidente della Repubblica: Rome, Italy, 2019.

20. Decreto-legge 19 Maggio 2020, n. 34. Misure Urgenti in Materia di Salute, Sostegno al Lavoro e All'economia, Nonché' di Politiche Sociali Connesse All'emergenza Epidemiologica da COVID-19, Pubblicato su Gazzetta Ufficiale Serie Generale n.128 del 19-05-2020-Suppl. Ordinario n. 21; Presidente della Repubblica: Rome, Italy, 2020.

21. Bertini, I.; Puglisi, G.; Marani, M.; Federici, A.; Preziosi, M.; Viola, C. Rapporto Annuale Efficienza Energetica 2020, ENEA; ENEA-Agenzia Nazionale Efficienza Energetica: Rome, Italy, 2020.

22. Decreto 26 Giugno 2015 Applicazione delle Metodologie di Calcolo delle Prestazioni Energetiche e Definizione delle Prescrizioni e Dei Requisiti Minimi Degli Edifici, Pubblicato su Gazzetta Ufficiale Serie Generale n.162 del 15-07-2015-Suppl. Ordinario n. 39; Ministero dello Sviluppo Economico: Rome, Italy, 2015.

23. Manioğlu, G.; Yılmaz, Z. Economic evaluation of the building envelope and operation period of heating system in terms of thermal comfort. Energy Build. 2006, 38, 266-272. [CrossRef]

24. Thalfeldt, M.; Pikas, E.; Kurnitski, J.; Voll, H. Facade design principles for nearly zero energy buildings in a cold climate. Energy Build. 2013, 67, 309-321. [CrossRef]

25. Lechner, N. Heating, Cooling, Lighting—Design Methods for Architects, 3rd ed.; John Wiley \& Sons Inc.: Hoboken, NJ, USA, 2008.

26. Sassine, E. A practical method for in-situ thermal characterization of walls, Case Stud. Therm. Eng. 2016, 8, 84-93.

27. Dongmei, P.; Mingyin, C.; Shiming, D.; Zhongping, L. The effects of external wall insulation thickness on annual cooling and heating energy uses under different climates. Appl. Energy 2012, 97, 313-318.

28. Kinnane, O.; Sinnott, D.; Turner, W.J.N. Evaluation of passive ventilation provision in domestic housing retrofit. Build Environ 2016, 106, 205-218. [CrossRef]

29. Broderick, A.; Byrne, M.; Armstrong, S.; Sheahan, J.; Coggins, A.M. A pre and post evaluation of indoor air quality, ventilation, and thermal comfort in retrofitted co-operative social housing. Build. Environ. 2017, 122, 126-133. [CrossRef]

30. Thomas, L.P.; Marino, B.M.; Muñoz, N. Steady-state and time-dependent heat fluxes through building envelope walls: A quantitative analysis to determine their relative significance all year round. J. Build. Eng. 2020, 29, 101122. [CrossRef]

31. Reilly, A.; Kinnane, O. The impact of thermal mass on building energy consumption. Appl. Energy 2017, 198, 108-121. [CrossRef]

32. Ascione, F.; Bianco, N.; Mauro, G.M.; Napolitano, D.F. Building envelope design: Multi-objective optimization to minimize energy consumption, global cost and thermal discomfort. Application to different Italian climatic zone. Energy 2019, 174, 359-374. [CrossRef]

33. Matos, M.; Soares, L.; Silva, L.; Sequeira, P. Life Cycle Assessment of an ETICS System Composed of a Natural Insulation Material : A Case Study of a System Using an Insulation Cork Board (ICB). In Portugal SB13 Contribution of Sustainable Building to Meet EU 20-20-20 Targets; Multicomp—Artes Gráficas, Lda: Guimarães, Portugal, 2013; Chapter 11; pp. 855-862.

34. Luján, S.V.; Arrebola, C.V.; Sánchez, A.R.; Benito, P.A.; Cortina, M.G. Experimental comparative study of the thermal performance of the façade of a building refurbished using ETICS, and quantification of improvements. Sustain. Cities Soc. 2019, 51, 101713. [CrossRef]

35. Gonçalves, M.; Simões, N.; Serra, C.; Flores-Colen, I. A review of the challenges posed by the use of vacuum panels in external insulation finishing systems. Appl. Energy 2020, 257, 114028. [CrossRef]

36. Sierra-Pérez, J.; Boschmonart-Rives, J.; Gabarrell, X. Environmental assessment of façade-building systems and thermal insulation materials for different climatic conditions. J. Clean. Prod. 2016, 113, 102-113. [CrossRef]

37. Donnarumma, G.; Fiore, P. A Multi-Criteria Model for the Comparison of Building Envelope Energy Retrofits. Mod. Environ. Sci. Eng. 2017, 3, 511-518. [CrossRef]

38. Bragança, L.; Pinheiro, M.; Mateus, R.; Amoêda, R.; Almeida, M.G.D.; Mendonça, P.; Cunha, A.M.; Dias, A.B.; Farinha, F.; Gervásio, H.; et al. Portugal SB10 Sustainable Building Affordable to All. Low Cost Sustainable Solutions. 2010. Available online: https:/ / repositorium.sdum.uminho.pt/handle/1822/22824 (accessed on 20 January 2021). 
39. Marques, C.; de Brito, J.; Silva, A. Application of the Factor Method to the Service Life Prediction of Etics. Int. J. Strateg. Prop. Manag. 2018, 22, 204-222. [CrossRef]

40. Mandilaras, I.; Atsonios, I.; Zannis, G.; Founti, M. Thermal performance of a building envelope incorporating ETICS with vacuum insulation panels and EPS. Energy Build. 2014, 85, 654-665. [CrossRef]

41. Saaty, T.L. Multicriteria Decision Making-The Analytic Hierarchy Process. Planning, Priority Setting, Resource Allocation; RWS Publishing: Pittsburgh, PA, USA, 1988.

42. Ching-Lai, H.; Kwangsun, Y. Multiple Attribute Decision Making; Springer: New York, NY, USA, 1981.

43. Saaty, T.L. Deriving the AHP 1-9 scale from first principles. In Proceedings of the ISAHP 2001, Berne, Switzerland, $2-4$ August 2001.

44. Saaty, T.L. Scaling Method for Priorities in Hierarchy Structures. J. Math. Psychol. 1977, 15, 234-281. [CrossRef]

45. UNI EN ISO 6946:2018. Componenti ed Elementi per Edilizia-Resistenza Termica e Trasmittanza Termica-Metodi di Calcolo. Available online: http:/ / store.uni.com/catalogo/uni-en-iso-6946-2018 (accessed on 18 January 2021).

46. UNI EN ISO 13786:2008. Prestazione Termica dei Componenti per Edilizia—Caratteristiche Termiche Dinamiche-Metodi di Calcolo. Available online: http:/ / store.uni.com/catalogo/uni-en-iso-13786-2008 (accessed on 18 January 2021).

47. Ministero dell'Ambiente e Della Tutela del Territorio e del Mare (MATTM). 2017 Criteri Ambientali Minimi per L'affidamento di Servizi di Progettazione e Lavori per la Nuova Costruzione, Ristrutturazione e Manutenzione di Edifici Pubblici. Available online: https: / / www.anit.it/wp-content/uploads/2017/11/DM-11-ottobre-2017.pdf (accessed on 18 January 2021).

48. UNI/PdR 13.1:2019. Sostenibilità Ambientale Nelle Costruzioni-Strumenti Operativi per la Valutazione Della SostenibilitàEdifici Residenziali. Available online: http:/ / store.uni.com/catalogo/uni-pdr-13-1-2019 (accessed on 18 January 2021).

49. UNI EN 15804:2014. Sostenibilità delle Costruzioni-Dichiarazioni Ambientali di Prodotto-Regole Quadro di Sviluppo per Categoria di Prodotto. Available online: http:/ / store.uni.com/catalogo/uni-en-15804-2014 (accessed on 18 January 2021).

50. UNI EN ISO 14025:2010. Etichette e Dichiarazioni Ambientali-Dichiarazioni Ambientali di Tipo III-Principi e Procedure. Available online: http:/ / store.uni.com/catalogo/uni-en-iso-14025-2010 (accessed on 18 January 2021).

51. UNI EN ISO 14021:2016. Etichette e Dichiarazioni Ambientali-Asserzioni Ambientali auto-Dichiarate (Etichettatura Ambientale di Tipo II). Available online: http:/ / store.uni.com/catalogo/uni-en-iso-14021-2016 (accessed on 18 January 2021).

52. ICE Database, Inventory of Carbon and Energy Database. Available online: https:/ / circularecology.com/ (accessed on 18 January 2021).

53. UNI 10349-1:2016. Riscaldamento e Raffrescamento Degli Edifici-Dati Climatici-Parte 1: Medie Mensili per la Valutazione Della Prestazione Termo-Energetica Dell'edificio e Metodi per Ripartire L'irradianza Solare Nella Frazione Diretta e Diffusa e per Calcolare L'irradianza Solare su di una Superficie Inclinata. Available online: http:/ /store.uni.com/catalogo/uni-10349-1-2016 (accessed on 18 January 2021).

54. Di Perna, C.; Stazi, F.; Casalena, A.U.; Stazi, A. Massa e comfort: Necessità di una adeguata capacità termica areica interna periodica. Costr. Laterizio 2008, 126, 52-59.

55. UNI EN ISO 717-1:2013. Acustica-Valutazione Dell'isolamento Acustico in Edifici e di Elementi di Edificio-Parte 1: Isolamento Acustico per via Aerea. Available online: http:/ / store.uni.com/catalogo/uni-en-iso-717-1-2013 (accessed on 18 January 2021).

56. Gazzetta Ufficiale Della Repubblica Italiana. D.P.C.M. 5 dicembre 1997—Determinazione dei Requisiti Acustici Passivi Degli Edifici.1997. Available online: https:/ / www.gazzettaufficiale.it/eli/gu/1997/12/22/297/sg/pdf (accessed on 28 November 2020).

57. Corrado, V.; Ballarini, I.; Corgnati, S.P. (a cura di). Building Typology Brochure. 2014. Available online: https:/ / episcope.eu/ fileadmin/tabula/public/docs/brochure/IT_TABULA_TypologyBrochure_POLITO.pdf (accessed on 18 January 2021).

58. EPISCOPE. Monitor Progress towards Climate Targets in European Housing Stocks. Available online: https://episcope.eu/ welcome/ (accessed on 28 November 2020).

59. LEGGE 30 marzo 1976, n. 373 Norme per il Contenimento del Consumo Energetico per usi Termici Negli Edifici. (GU Serie Generale n.148 del 07-06-1976). Available online: https:/ / www.gazzettaufficiale.it/eli/id/1976/06/07/076U0373/sg (accessed on 20 January 2021).

60. LEGGE 9 gennaio 1991, n. 10 Norme per L'attuazione del Piano Energetico Nazionale in Materia di uso Razionale Dell'energia, di Risparmio Energetico e di Sviluppo delle Fonti Rinnovabili di Energia. (GU Serie Generale n.13 del 16-01-1991—Suppl. Ordinario n. 6). Available online: https:/ / www.gazzettaufficiale.it/eli/id/1991/01/16/091G0015/sg (accessed on 20 January 2021).

61. DECRETO DEL PRESIDENTE DELLA REPUBBLICA 26 agosto 1993, n. 412 Regolamento Recante Norme per la Progettazione, L'installazione, L'esercizio e la Manutenzione Degli Impianti Termici Degli Edifici ai fini del Contenimento dei Consumi di Energia, in Attuazione dell'art. 4, comma 4, Della Legge 9 Gennaio 1991, n. 10. (GU Serie Generale n.242 del 14-10-1993Suppl. Ordinario n. 96). Available online: https://www.gazzettaufficiale.it/eli/id/1993/10/14/093G0451/sg (accessed on 20 January 2021). 